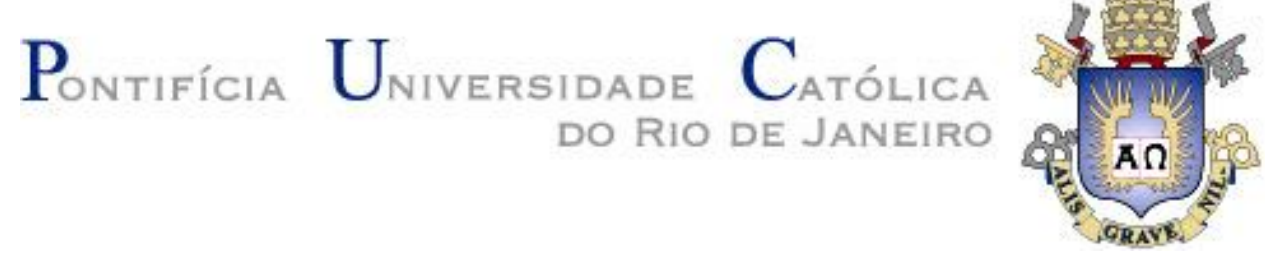

Gleyd Oliveira dos Santos

\begin{abstract}
Aplicação de Curvas de Bézier para o Estudo de Funções Polinomiais no Ensino Médio.
\end{abstract}

Dissertação apresentada ao Programa de Pós-Graduação em Matemática da PUC-Rio como requisito parcial para obtenção do grau de Mestre em Matemática.

Orientador: Prof. Sinesio Pesco

Rio de Janeiro

Março de 2015 


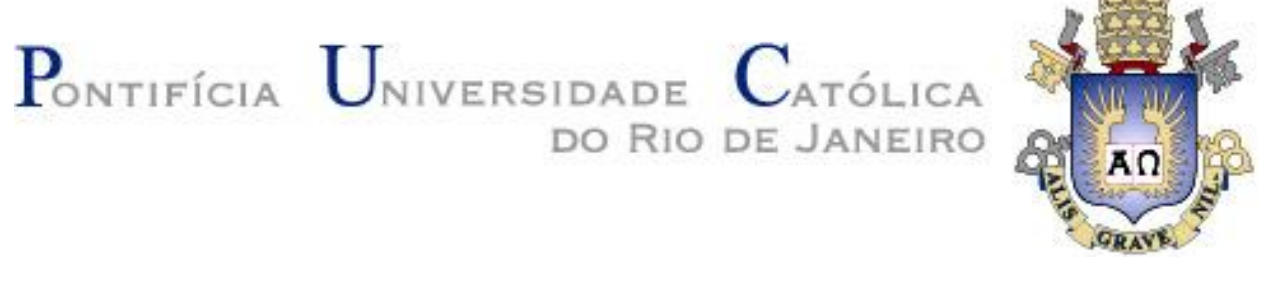

Gleyd Oliveira dos Santos

\section{Aplicação de Curvas de Bézier para o Estudo de Funções Polinomiais no Ensino Médio.}

Dissertação apresentada como requisito parcial para obtenção do grau de Mestre pelo Programa de PósGraduação em Matemática do Departamento de Matemática do Centro Técnico Científico da PUC-Rio. Aprovada pela Comissão Examinadora abaixo assinada.

Prof. Sinesio Pesco

Orientador

Departamento de Matemática - PUC-Rio

Prof. - Dirce Uesu Pesco

Departamento de Geometria - UFF

Prof. a Christine Sertã Costa

Departamento de Matemática - PUC-Rio

Prof. José Eugenio Leal

Coordenador Setorial do Centro

Técnico Científico - PUC-Rio

Rio de Janeiro, 26 de Março de 2015 
Todos os direitos reservados. É proibida a reprodução total ou parcial do trabalho sem autorização da universidade, do autor e do orientador.

\section{Gleyd Oliveira dos Santos}

Graduou-se em Licenciatura em Matemática na UFF (Universidade Federal Fluminense) em 2011. Atualmente é professora efetiva da Secretaria de Educação do Estado do Rio de Janeiro.

Ficha Catalográfica

Santos, Gleyd Oliveira dos

Aplicação de Curvas de Bézier para o estudo de funções polinomiais no Ensino Médio / Gleyd Oliveira dos Santos ; orientador: Sinesio Pesco. - 2015.

50 f. : il. (color.) ; $30 \mathrm{~cm}$

Dissertação (mestrado)-Pontifícia Universidade Católica do Rio de Janeiro, Departamento de Matemática, 2015.

Inclui bibliografia

1. Matemática - Teses. 2. Curvas de Bézier. 3. Algoritmo de De Casteljau. 4. Bézier não paramétrico. 5. Função polinomial. I. Pesco, Sinesio. II. Pontifícia Universidade Católica do Rio de Janeiro. Departamento de Matemática. III. Título.

CDD: 510 
Dedico esse trabalho a minha mãe, por todo seu esforço para me dar educação, atenção e carinho.

A minha família pelo apoio e compreensão.

Ao meu grande amor, Henrique, por estar ao meu lado em todos os momentos. 


\section{Agradecimentos}

Antes de tudo, agradeço a Deus, meu Mestre e Criador, pela sabedoria e força a mim concedidas. E por ter colocado pessoas mais que importantes no meu caminho.

A CAPES e à PUC-Rio, pelos auxílios concedidos, sem os quais este trabalho não poderia ter sido realizado.

Ao meu orientador Sinesio Pesco pelo apoio, aprendizado, colaboração, confiança e oportunidade de trabalhar ao seu lado.

Aos professores que contribuíram diretamente nesta minha pós-graduação: Nicolau Saldanha; Christine Sertã Costa; Marcos Craizer; Eduardo Barbosa Pinheiro; Juliana Abrantes Freire; Débora Freire Mondaini e Carlos Frederico Palmeira.

À minha mãe Regina, por se orgulhar de mim, por me fazer acreditar que sou capaz e por sua ajuda incondicional.

Às minhas tias, Sheila e Nazareth, e ao meu tio Amilson, meu agradecimento especial, por sempre estarem ao meu lado e por acreditarem em mim.

Ao meu namorado, Henrique, pela compreensão.

Aos colegas de turma pelo incentivo e companheirismo.

Às minhas amigas Bruna, Érica, Renata e Thaís, por esclarecerem minhas dúvidas e por terem tornado meu trabalho mais leve e agradável. 


\section{Resumo}

Santos, Gleyd Oliveira dos; Pesco, Sinesio (Orientador). Aplicação de Curvas de Bézier para o Estudo de Funções Polinomiais no Ensino Médio. Rio de Janeiro, 2015. 50p. Dissertação de Mestrado - Departamento de Matemática, Pontifícia Universidade Católica do Rio de Janeiro.

Neste trabalho apresentamos uma proposta para auxiliar o estudo de funções polinomiais no ensino médio por intermédio das Curvas de Bézier. Para isto introduzimos as curvas de Bézier utilizando o algoritmo de De Casteljau e discutimos suas propriedades. Em seguida aplicamos a formulação das curvas de Bézier não paramétricas para representar funções polinomiais e discutimos alguns resultados observados em sala de aula.

\section{Palavras-chave}

Curvas de Bézier; algoritmo de De Casteljau; Bézier não paramétrico; função polinomial. 


\section{Abstract}

Santos, Gleyd Oliveira dos; Pesco, Sinesio (Advisor). Bézier Curves application for the study of polynomial functions in high school. Rio de Janeiro, 2015. 50p. MSc. Dissertation - Departamento de Matemática, Pontifícia Universidade Católica do Rio de Janeiro.

In this work we present a proposal to assist the study of polynomial functions in high school through the Bezier curves. For this we introduce the Bezier curves using the De Casteljau algorithm and discuss its properties. Then apply the formulation of Bezier curves non-parametric to represent polynomial functions and discuss some results observed in the classroom.

\section{Keywords}

Bezier Curves; De Casteljau's Algorithm; Non-parametric Bezier; Polynomial function. 


\section{Sumário}

$\begin{array}{ll}\text { 1. Introdução } & 12\end{array}$

2. Curvas de Bézier 15

2.1. Algoritmo de De Casteljau $\quad 15$

2.2. Definição de Bézier 17

2.3. Propriedades 19

2.4. Exemplos 22

3. Bézier não paramétrico 28

3.1. Formulação não paramétrica 28

đิ $\quad$ 4. Resultados em sala de aula 34

5. Conclusão 45

6. Referências Bibliográficas 46

$\begin{array}{lll}\text { 7. Anexos } & 47\end{array}$

7.1. Questionário 47

7.2. Resposta dos Alunos 48

7.3. Auto Avaliação $\quad 50$ 


\section{Lista de figuras}

Figura 01 - A Chords Bridge é uma ponte que lembra o algo- 12 ritmo de De Casteljau na arquitetura e engenharia.

Figura 02 - Algumas curvas de Bézier usadas para fazer as 13 letras "a", "g" e "r".

Figura 03 - Ponto $\mathrm{P}$ correspondente a t sobre o segmento $\mathrm{P}_{0} \mathrm{P}_{1}$. 15

Figura 04 - Pontos $\mathrm{P}_{0}, \mathrm{P}_{1}$ e $\mathrm{P}_{2}$ e os segmentos $\mathrm{P}_{0} \mathrm{P}_{1}$ e $\mathrm{P}_{1} \mathrm{P}_{2}$. 16

Figura 05 - Pontos $\mathrm{P}_{0}^{1}\left(\frac{1}{5}\right), \mathrm{P}_{1}^{1}\left(\frac{1}{5}\right)$ e segmento $\mathrm{P}_{0}^{1} \mathrm{P}_{1}^{1}$. 16

Figura 06 - Ponto $\mathrm{P}_{0}^{2}\left(\frac{1}{5}\right)$ sobre o segmento $\mathrm{P}_{0}^{1} \mathrm{P}_{1}^{1}$. 17

Figura 07 - Ponto $\mathrm{P}_{0}^{2}\left(\frac{1}{5}\right)$ e a curva de Bézier de grau 2.

Figura 08 - Polígono de controle e curva de Bézier. 19

Figura 09 - Fecho convexo contendo a curva. 20

Figura 10 - Modelagem através do polígono de controle. 21

Figura 11 - Pseudo controle local com 4 pontos de controle. 21

Figura 12 - Pseudo controle local com 11 pontos de controle. 22

Figura 13 - Curva de Bézier gerada pelos pontos $(1,1),(0,0)$ e 23 $(1,1)$.

Figura 14 - Curva de Bézier gerada pelos pontos $(-1,1),(0,-1) 24$ e $(1,1)$.

Figura 15 - Curva de Bézier gerada pelos pontos $(1,1),(2,2)$ e 25 $(3,1)$.

Figura 16 - Generalização da curva de Bézier com 3 pontos de 25 controle.

Figura 17 - Generalização da curva de Bézier com 4 pontos de 26 controle.

Figura 18 - Gráfico da função $y(t)=t^{2}$. 29

Figura 19 - Gráfico da função $\mathrm{y}(\mathrm{t})=\mathrm{t}^{3}$. 32

Figura 20 - Gráfico do polinômio $\mathrm{y}(\mathrm{t})=-3 \mathrm{t}^{3}+\frac{9}{2} \mathrm{t}^{2}-\frac{1}{2} \mathrm{t}$. 33

Figura 21 - Aparato de madeira e elásticos, construído para 34

Figura 22 - Fotos da Oficina. 35

Figura 23 - Algoritmo de De Casteljau com 3 pontos de controle. 37

Figura 24 - Campo de entrada: parametrização de um seg- 37 mento.

Figura 25 - Algoritmo de De Casteljau com 4 pontos de controle. 38 
Figura 26 - Campo de entrada: divisão do segmento em 10 par- 38 tes iguais.

Figura 27 - Algoritmo de De Casteljau, construção livre. 39

Figura 28 - Bézier não paramétrico, janela CAS mostrando a 40 formulação polinomial.

Figura 29 - Bézier não paramétrico, janela visualização mos- 40 trando a curva de Bézier e o gráfico da função $\mathrm{f}(\mathrm{x})=$ $\mathrm{x}^{3}$.

Figura 30 Bézier não paramétrico, janela de visualização mos- 41 trando curva de Bézier com uma casa decimal.

Figura 31 Bézier não paramétrico, janela de visualização mos- 41 trando curva de Bézier com três casas decimais.

Figura 32 - Janela de álgebra mostrando a função gerada pelos 42 coeficientes a, b e c.

Figura 33 - Inserindo os pontos na planilha. $\quad 42$

Figura 34 - Subníveis gerados na planilha. 43

Figura 35 - Curva de Bézier e Algoritmo de De Casteljau com 43 seus níveis. 
"Sempre me pareceu estranho que todos aqueles que estudam seriamente esta ciência (matemática) acabam tomados de uma espécie de paixão pela mesma. Em verdade, o que proporciona o máximo de prazer não é o conhecimento e sim a aprendizagem, não é a posse, mas a aquisição, não é a presença, mas o ato de atingir a meta."

Carl Friedrich Gauss 


\section{Introdução}

Paul de Casteljau, nasceu em 1930, na França, tornou-se físico e um grande matemático. Por volta de 1958, quando trabalhava na Citroën, de Casteljau concebeu um sistema de algoritmos que calculava um certo grupo de curvas, conhecido hoje como algoritmo de De Casteljau, que foi usado para o design de automóveis.

Segundo Gerald Farin, em seu livro, Curves and Surfaces for CAGD (1992, p.2), “Citroën mantinha segredo sobre os resultados obtidos por Paul de Casteljau, e fez o famoso relatório técnico MAC-TR-41 (por S.A. Coons) não aparecer antes de 1967", os resultados de sua obra foram impressos apenas em 1975. Durante esse período, vários trabalhos foram surgindo, embora abordados de outra forma. Um outro francês, Pierre Bézier Étienne, engenheiro e funcionário da Renault, divulgou um novo trabalho que intitulou "Curvas de Bézier" (equivalente ao algoritmo de De Casteljau), tornando-se líder na transformação de design de automóveis.

A curva de Bézier é uma curva paramétrica ${ }^{1}$, que foi desenvolvida para a confecção de automóveis na montadora Renault. Além da grande utilização nas industrias automotivas, a curva de Bézier é amplamente usada na computação gráfica e no design de produtos, arquitetura, engenharia, entre outros.
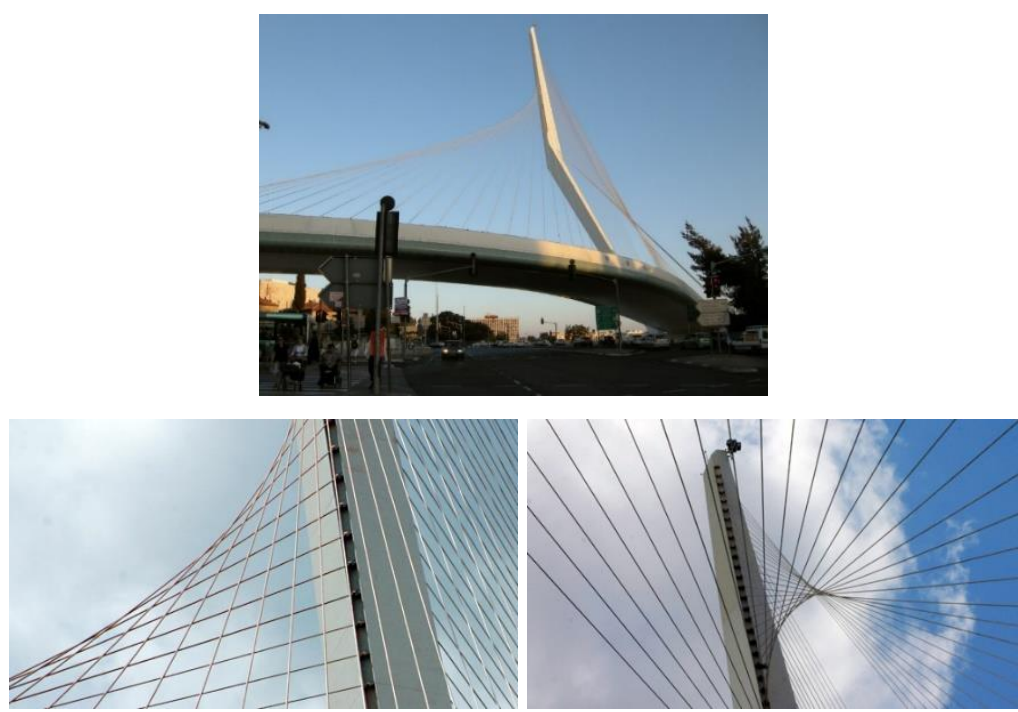

Figura 01 - A Chords Bridge é uma ponte que lembra o algoritmo de De Casteljau na arquitetura e engenharia.

${ }^{1}$ Curva Paramétrica: É uma curva que expressa o valor de cada variável x,y em função de uma variável independente t, que é chamada de parâmetro. 
Alguns programas que aplicam a curva de Bézier são por exemplo: Adobe Illustrator, CorelDraw, Inkscape e Photoshop. Eles a utilizam para criar um logotipo; vetorizar uma imagem; modelar e desenhar curvas (assim como veremos na propriedade 3); etc.

Um uso também muito comum das curvas de Bézier está nas fontes de computador, que são confeccionadas através da composição de várias dessas curvas.
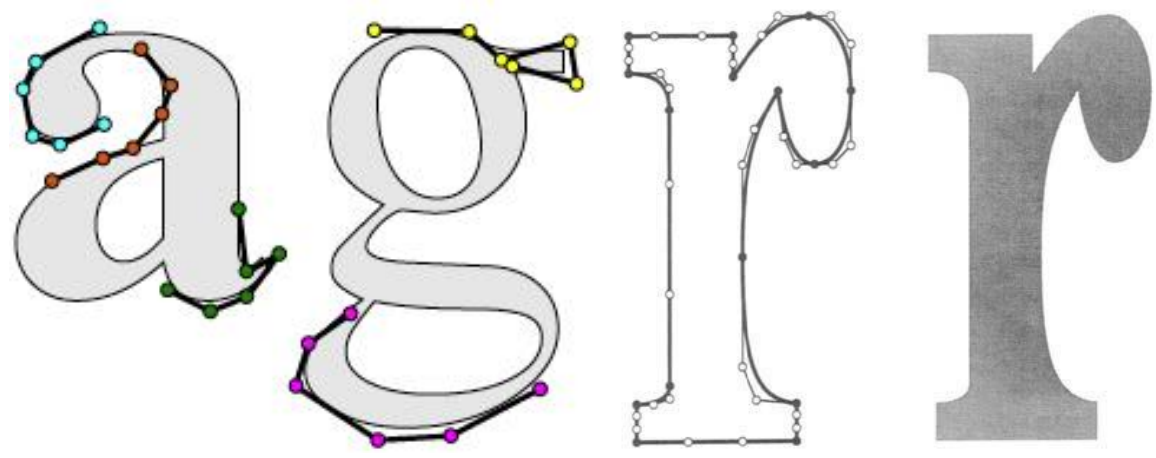

Figura 02 - Algumas curvas de Bézier usados para fazer as letras "a", "g" e "r".

O objetivo deste trabalho é introduzir este importante conceito aos alunos do ensino médio como uma motivação ao estudo de polinômios (já que o estudo de polinômios é um dos instrumentos mais explorados para se desenhar curvas) e mostrar como trabalhar com a curva de Bézier através do algoritmo de De Casteljau. Para isso, vamos desenvolver instrumentos e estratégias que facilitem o processo de aprendizagem.

A principal questão é como introduzir no ensino médio as curvas de Bézier. Uma das dificuldades encontradas para se trabalhar esse assunto é que essa curva lida com o modelo paramétrico. Apesar do aluno estar acostumado com alguns programas que desenham curvas, por exemplo o Paint Brush, ainda assim, ele não tem elementos matemáticos suficientes. E quais elementos matemáticos ele tem? As funções polinomiais. Assim, nossa estratégia foi buscar um modelo de curvas de Bézier restrito ao caso em que se reduzam ao gráfico de um polinômio, mas de forma que ainda possamos explorar as interessantes propriedades destas curvas.

De acordo com o currículo mínimo obrigatório, esse trabalho pode ser aplicado como auxílio ao estudo de polinômios a partir do $8^{\circ}$ ano do ensino fundamental, nesse ano pode-se trabalhar com a representação geométrica de um polinômio 
de diferentes graus, já no $9^{\circ}$ ano o trabalho pode ser focado nas equações do $2^{\circ}$ grau, que é um assunto de grande importância. No ensino médio, podemos trabalhar, por exemplo, com funções polinomiais do $1^{\circ}$ e $2^{\circ}$ grau, polinômios e equações algébricas.

Este trabalho foi dividido nos seguintes capítulos: No Capitulo 2 vamos estudar o método recursivo de De Casteljau, definir a curva de Bézier e apresentar algumas propriedades da curva e veremos exemplos. No capítulo 3 introduziremos uma formulação que irá restringir as curvas de Bézier ao gráfico de uma função polinomial. No capítulo 4 atividades serão propostas e aplicadas para alunos do ensino fundamental e médio; mostraremos alguns dos resultados obtidos 


\section{2 \\ Curvas de Bézier}

Neste capítulo apresentaremos a definição da curva de Bézier, primeiro utilizando o algoritmo de De Casteljau, depois a formulação de Bézier e algumas propriedades e exemplos.

\section{1}

\section{Algoritmo de De Casteljau}

O algoritmo de De Casteljau é um método para gerar as curvas de Bézier aplicando repetidas interpolações lineares, ou seja, vamos obter um segmento de reta que passa por dois pontos de controle consecutivos, $\mathrm{P}_{0} \mathrm{P}_{1}, \mathrm{P}_{1} \mathrm{P}_{2}, \ldots, \mathrm{P}_{\mathrm{n}-1} \mathrm{P}_{\mathrm{n}}$. Esse processo será feito por $n-1$ vezes, e assim encontraremos o ponto que pertencerá a curva.

Vamos ilustrar o algoritmo de De Casteljau construindo uma curva de Bézier de grau 2, usando a interpretação geométrica do algoritmo.

Para isso, precisamos escolher um parâmetro t, no mínimo tomar 3 pontos distintos quaisquer (que serão os pontos de controle da curva), através das interpolações iremos obter o ponto $\mathrm{P}(\mathrm{t})$ que pertence a curva, fazendo o parâmetro t variar de 0 a 1, teremos a curva de Bézier desejada.

Para determinarmos, por exemplo, o ponto $\mathrm{P}\left(\frac{1}{5}\right)$ pertencente a curva, vamos proceder do seguinte modo:

- $\quad$ Primeiramente vamos escolher o parâmetro $t=\frac{1}{5}, t \in[0,1]$.

- Dado um segmento $\mathrm{P}_{0} \mathrm{P}_{1}$ e um parâmetro t, obtemos um ponto $\mathrm{P}$ correspondente a t sobre o segmento $\mathrm{P}_{0} \mathrm{P}_{1}$, pela equação paramétrica da reta:

$$
P(t)=(1-t) \cdot P_{0}+t \cdot P_{1}
$$




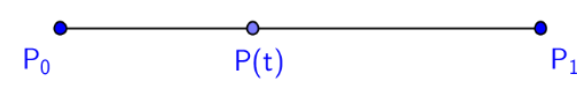

Figura 03: Ponto $P$ correspondente a t sobre o segmento $P_{0} P_{1}$.

Utilizaremos a notação $\mathrm{P}_{\mathrm{i}}^{\mathrm{r}}(\mathrm{t})$ para significar o ponto $\mathrm{P}(\mathrm{t})$ sobre o segmento $\mathrm{P}_{\mathrm{i}} \mathrm{P}_{\mathrm{i}+1}$ e $\mathrm{r}=1, \ldots, \mathrm{n}$ o nível de recursão ${ }^{2}$ que indicará o avanço nas repetidas interpolações lineares. Neste exemplo de uma curva de grau 2 temos que $n=2$.

- $\quad$ Sejam os pontos $\mathrm{P}_{0}, \mathrm{P}_{1}$ e $\mathrm{P}_{2}$ e os segmentos $\mathrm{P}_{0} \mathrm{P}_{1}$ e $\mathrm{P}_{1} \mathrm{P}_{2}$.

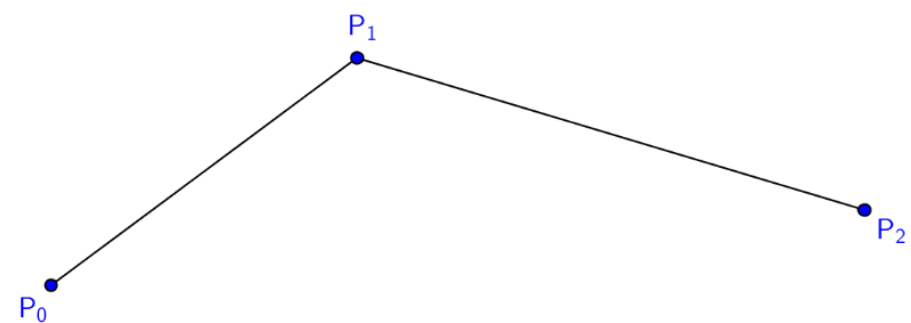

Figura 04: Pontos $P_{0}, P_{1}$ e $P_{2}$ e os segmentos $P_{0} P_{1}$ e $P_{1} P_{2}$.

- $\quad$ No primeiro nível de recursão, $\mathrm{n}=1$, vamos obter os pontos $\mathrm{P}_{0}^{1}\left(\frac{1}{5}\right), \mathrm{P}_{1}^{1}\left(\frac{1}{5}\right)$ respectivamente sobre o segmento $\mathrm{P}_{0} \mathrm{P}_{1}$ e $\mathrm{P}_{1} \mathrm{P}_{2}$. A partir desses pontos obtemos o segmento $\mathrm{P}_{0}^{1} \mathrm{P}_{1}^{1}$.

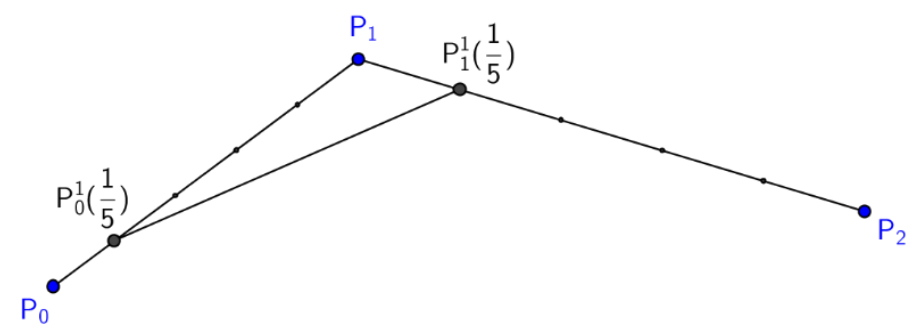

Figura 05: Pontos $\mathrm{P}_{0}^{1}\left(\frac{1}{5}\right), \mathrm{P}_{1}^{1}\left(\frac{1}{5}\right)$ e segmento $\mathrm{P}_{0}^{1} \mathrm{P}_{1}^{1}$.

- Passamos agora ao segundo nível de recursão, $\mathrm{n}=2$, e do mesmo modo, vamos encontrar o ponto $\mathrm{P}_{0}^{2}\left(\frac{1}{5}\right)$ sobre o segmento $\mathrm{P}_{0}^{1} \mathrm{P}_{1}^{1}$. Como estamos no nível 2 para uma curva de grau 2 , então o ponto $\mathrm{P}_{0}^{2}\left(\frac{1}{5}\right)$ é o ponto $\mathrm{P}\left(\frac{1}{5}\right)$ que buscamos.

${ }^{2}$ Recursão: Em computação, a recursividade é a definição de uma função que pode invocar a si mesma. 


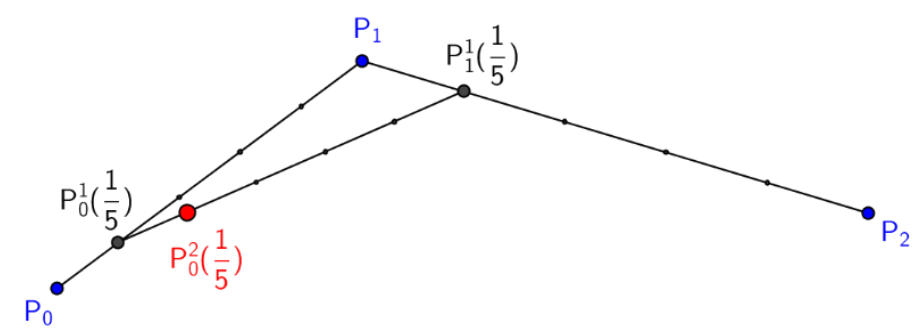

Figura 06: Ponto $\mathrm{P}_{0}^{2}\left(\frac{1}{5}\right)$ sobre o segmento $\mathrm{P}_{0}^{1} \mathrm{P}_{1}^{1}$.

- De forma análoga, podemos obter todos os pontos da curva, com $t \in[0,1]$.

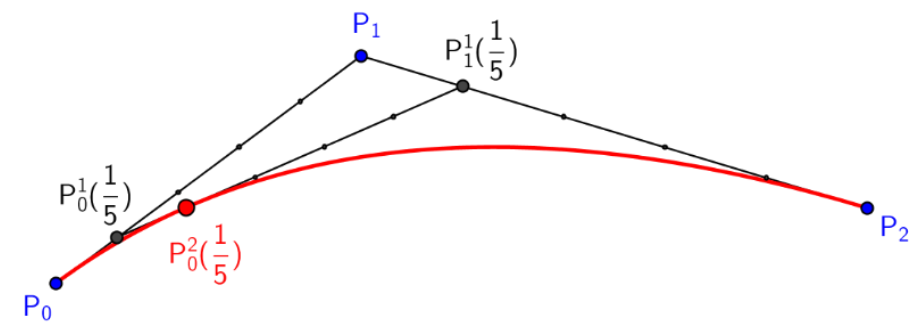

Figura 07: Ponto $\mathrm{P}_{0}^{2}\left(\frac{1}{5}\right)$ e a curva de Bézier de grau 2.

Segundo Farin, “a construção anterior para uma parábola pode ser generalizada para gerar uma curva polinomial de grau n arbitrária:

Dados os pontos $\mathrm{P}_{0}, \mathrm{P}_{1}, \ldots, \mathrm{P}_{\mathrm{n}}$ e $t \in \mathbb{R}$,

$$
P_{i}^{r}(t)=(1-t) \cdot P_{i}^{r-1}(t)+t \cdot P_{i+1}^{r-1}(t) \quad\left\{\begin{array}{c}
r=1, \ldots, n \\
i=0, \ldots, n-r
\end{array}\right.
$$

e $\mathrm{P}_{\mathrm{i}}^{0}(\mathrm{t})=\mathrm{P}_{\mathrm{i}}$. Então $\mathrm{P}_{0}^{\mathrm{n}}(\mathrm{t})$ é o ponto com o valor do parâmetro t na curva de Bézier, por conseguinte, $\mathrm{P}_{0}^{\mathrm{n}}(\mathrm{t})=\mathrm{P}^{\mathrm{n}}$."

\section{2}

\section{Definição de Bézier}

A curva de Bézier, como já vimos, é uma curva paramétrica. Definida através de um parâmetro $t \in(0,1)$ e de seus pontos de controle.

Vamos expressar a curva de Bézier aplicando uma outra formulação em termos de polinômios de Bernstein, [Farin]: 


$$
\begin{gathered}
B(t)=\sum_{i=0}^{n}\left(\begin{array}{l}
n \\
i
\end{array}\right) \cdot P_{i} \cdot(1-t)^{n-i} \cdot t^{i} \\
B(t)=(1-t)^{n} \cdot P_{0}+\left(\begin{array}{l}
n \\
1
\end{array}\right) \cdot(1-t)^{n-1} \cdot t \cdot P_{1}+\cdots+\left(\begin{array}{c}
n \\
n-1
\end{array}\right) \cdot(1-t) \cdot t^{n-1} \cdot P_{n-1} \\
+t^{n} \cdot P_{n}
\end{gathered}
$$

Onde $\mathrm{P}_{\mathrm{i}}$ é um ponto de controle e $\left(\begin{array}{c}\mathrm{n} \\ \mathrm{i}\end{array}\right)=\frac{\mathrm{n} !}{\mathrm{i} !(\mathrm{n}-\mathrm{i}) !}$.

Os índices são:

- $\quad \mathrm{t}:$ um parâmetro real, $\mathrm{t} \in[0,1]$;

- $\quad$ n: o grau da curva;

- $\quad$ i: um parâmetro inteiro, cujo valor varia de 0 até $\mathrm{n}$.

Como exemplo, vamos obter a curva de Bézier de grau 4 , ou seja, $n=4$

$$
\begin{gathered}
B(t)=(1-t)^{4} \cdot P_{0}+\left(\begin{array}{l}
4 \\
1
\end{array}\right) \cdot(1-t)^{4-1} \cdot t \cdot P_{1}+\cdots+\left(\begin{array}{c}
4 \\
4-1
\end{array}\right) \cdot(1-t) \cdot t^{4-1} \cdot P_{4-1} \\
+t^{4} \cdot P_{4} \\
B(t)=(1-t)^{4} \cdot P_{0}+4 \cdot(1-t)^{3} \cdot t \cdot P_{1}+6 \cdot(1-t)^{2} \cdot t^{2} \cdot P_{2}+4 \cdot(1-t) \cdot t^{3} \cdot P_{3} \\
+t^{4} \cdot P_{4}, \quad t \in[0,1]
\end{gathered}
$$

A linha poligonal formada ligando-se os pontos $\mathrm{P}_{0}, \mathrm{P}_{1}, \mathrm{P}_{2}, \ldots, \mathrm{P}_{\mathrm{n}}$ é chamada de polígono de Bézier ou polígono de controle. Da mesma forma, os $\mathrm{P}_{\mathrm{i}}$ pontos do polígono são chamados de pontos de controle ou pontos de Bézier. Por exemplo, se quisermos obter uma curva de grau 5 , ou seja, $\mathrm{n}=5$, basta tomarmos no mínimo $\mathrm{n}+1=6$ pontos de controle. Ou vice-versa, se utilizarmos 3 pontos de controle obteremos uma curva de grau máximo 2 , tomando 4 pontos de controle teremos uma curva de grau máximo 3.

É possível verificar que a expressão polinomial da curva de Bézier e a fórmula geral recursiva de De Casteljau são equivalentes [Farin]. 


\section{3 \\ Propriedades}

O algoritmo de Casteljau nos permite inferir várias propriedades importantes da Curva de Bézier. Nesse trabalho vamos falar de quatro propriedades consideradas mais importantes, são elas: o fecho convexo, a interpolação de pontos finais, o design e o pseudo controle local.

1. Fecho convexo. "O fecho convexo de um conjunto de pontos é definido como o menor polígono convexo que contém todos os pontos." [Freitas]. Essa propriedade garante que a curva de Bézier estará totalmente contida nesse fecho. A demonstração disso pode ser vista em [Farin].

A figura 08 mostra o polígono de controle e sua respectiva curva de Bézier:

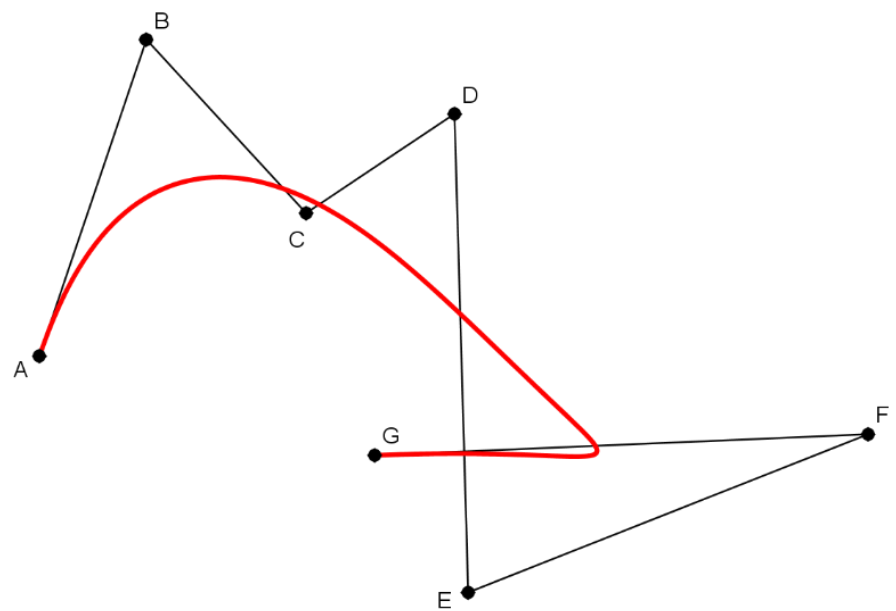

Figura 08: Polígono de controle e curva de Bézier.

Aqui mostramos a curva totalmente contida no fecho: 


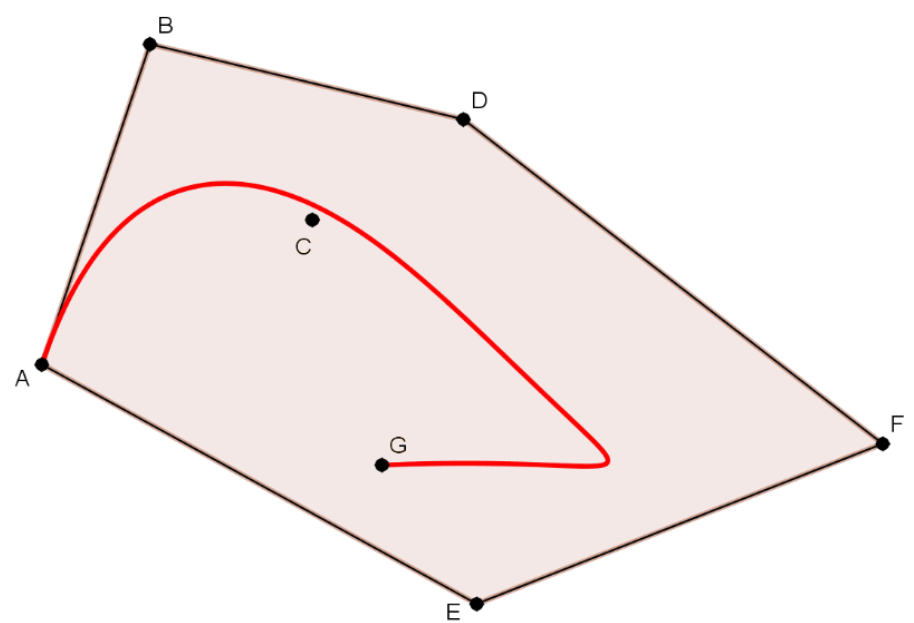

Figura 09: Fecho convexo contendo a curva.

2. Interpolação de pontos finais. $O$ primeiro e o último ponto de controle pertencem a curva. Isso pode ser verificado nos casos onde $t=0$ e $t=1$, por isso é importante o controle sobre esses pontos. Vejamos:

- $\quad$ Para $\mathrm{t}=0$ :

$B(0)=(1-0)^{n} \cdot P_{0}+\left(\begin{array}{l}n \\ 1\end{array}\right) \cdot(1-0)^{n-1} \cdot 0 \cdot P_{1}+\cdots+\left(\begin{array}{c}n \\ n-1\end{array}\right) \cdot(1-0) \cdot 0^{n-1} \cdot P_{n-1}$ $+0^{\mathrm{n}} \cdot \mathrm{P}_{\mathrm{n}}$

$$
\mathrm{B}(0)=1^{\mathrm{n}} \cdot \mathrm{P}_{0}=\mathrm{P}_{0}
$$

Onde $\mathrm{P}_{0}$ é o primeiro ponto.

- $\quad$ Para $\mathrm{t}=1$ :

$$
\begin{gathered}
B(1)=(1-1)^{n} \cdot P_{0}+\left(\begin{array}{l}
n \\
1
\end{array}\right) \cdot(1-1)^{n-1} \cdot 1 \cdot P_{1}+\cdots+\left(\begin{array}{c}
n \\
n-1
\end{array}\right) \cdot(1-1) \cdot 1^{n-1} \cdot P_{n-1} \\
+1^{n} \cdot P_{n} \\
B(1)=1^{n} \cdot P_{n}=P_{n}
\end{gathered}
$$

Onde $\mathrm{P}_{\mathrm{n}}$ é o último ponto.

3. Design com curvas de Bézier. A curva de Bézier é uma ferramenta muito útil na modelagem de curvas. Através do polígono de controle podemos pré-definir o formato da curva, ou seja, se quisermos fazer um "s" basta construirmos um polígono que se aproxime do desenho e depois fazermos os ajustes, como na figura 10: 

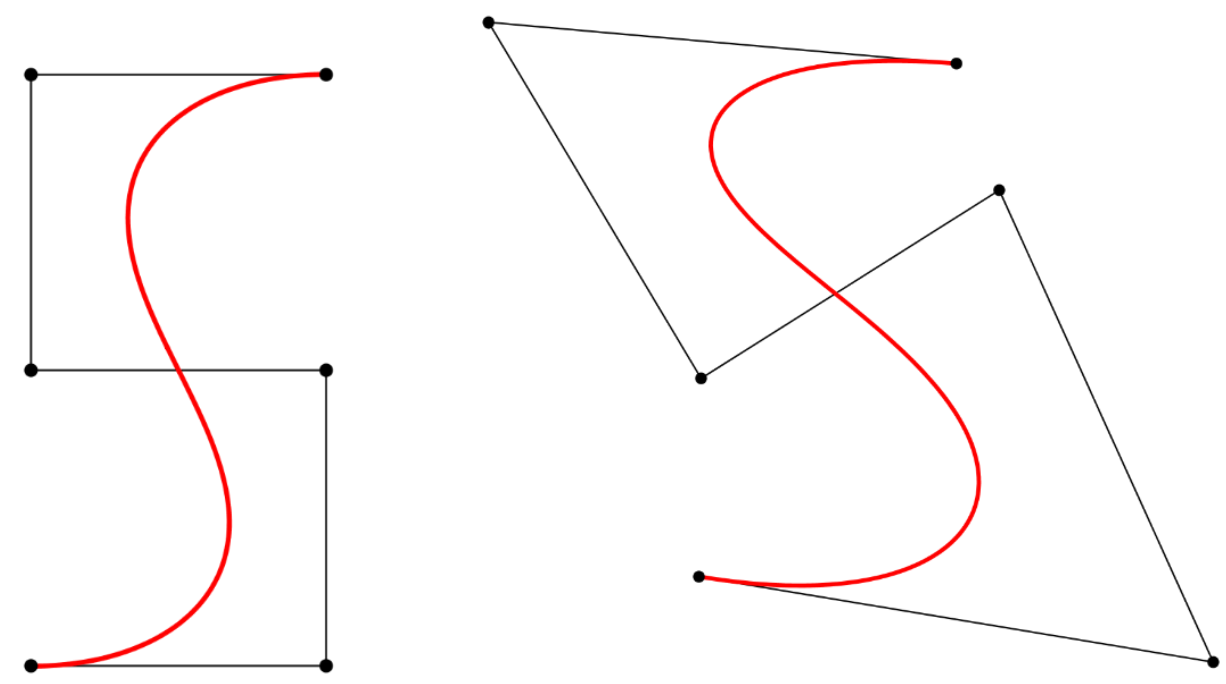

Figura 10: Modelagem através do polígono de controle.

4. Pseudo controle local. Dado uma curva de Bézier com $P_{n}$ pontos de controle. Ao mover apenas um dos vértices do polígono de controle, por exemplo $\mathrm{P}_{\mathrm{i}}$, a curva sofre uma mudança mais acentuada na região próxima ao ponto, um tanto previsível, embora a alteração afete toda a curva. Vejamos:

Nesse primeiro desenho podemos observar que grande parte da curva sofreu alteração, isso porque temos apenas 4 pontos de controle.

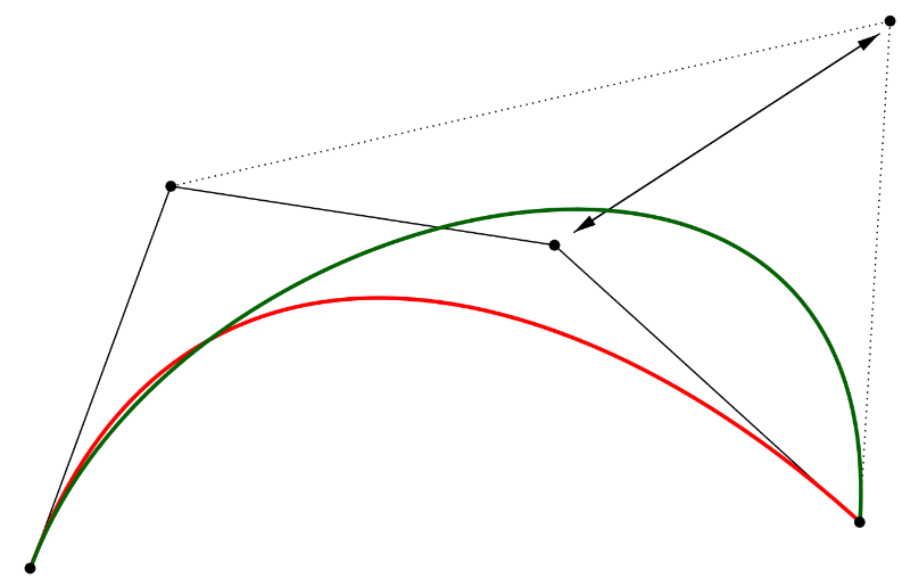

Figura 11: Pseudo controle local com 4 pontos de controle.

Nesse outro exemplo, com 11 pontos de controle, a curva sofreu uma deformação na vizinhança do ponto. A figura ilustra que a região mais próxima do ponto movimentado, sofre maior alteração. 


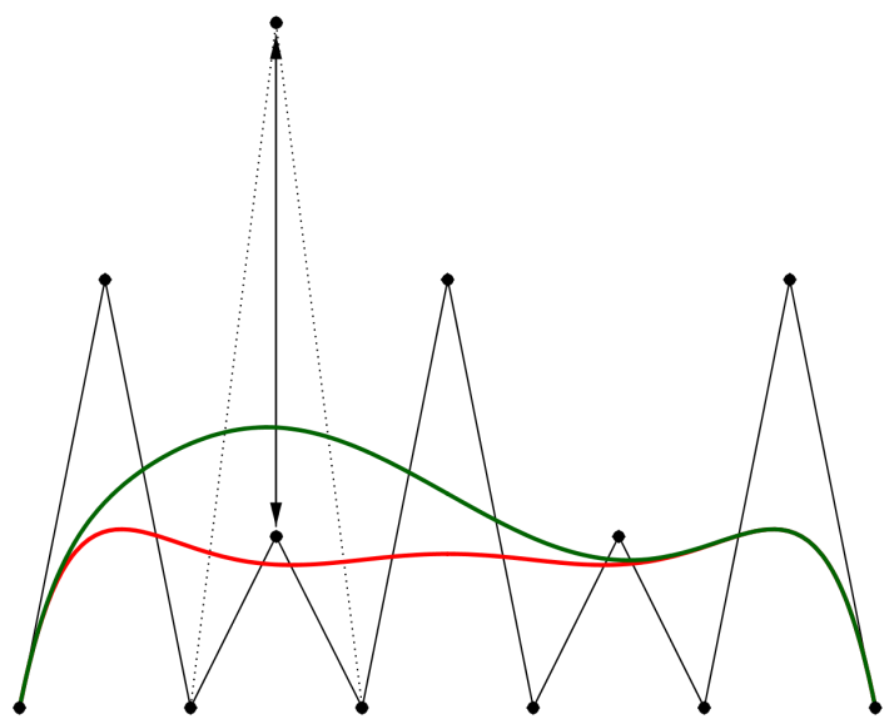

Figura 12: Pseudo controle local com 11 pontos de controle.

\section{4}

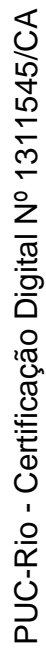

\section{Exemplos}

Vejamos alguns exemplos de como obter a equação paramétrica da curva de Bézier, dados os pontos de controle.

Exemplo 1: Encontrar a equação paramétrica da curva de Bézier gerada pelos pontos $(-1,1),(0,0)$ e $(1,1)$.

Sejam $P_{0}=(-1,1), P_{1}=(0,0)$ e $P_{2}=(1,1)$. Aplicando a equação paramétrica da reta temos:

$\mathrm{P}_{0}^{1}(\mathrm{t})=(1-\mathrm{t}) \cdot\left(\mathrm{P}_{0}\right)+\mathrm{t} .\left(\mathrm{P}_{1}\right)$

$P_{1}^{1}(t)=(1-t) \cdot\left(P_{1}\right)+t \cdot\left(P_{2}\right)$

Encontramos os pontos $\mathrm{P}_{0}^{1}(\mathrm{t})$ que pertence ao segmento $\mathrm{P}_{0} \mathrm{P}_{1}$ e $\mathrm{P}_{1}^{1}(\mathrm{t})$ que pertence ao segmento $P_{1} P_{2}$. De modo análogo, vamos encontrar o ponto $P_{0}^{2}(t)$ que pertence ao segmento $\mathrm{P}_{0}^{1} \mathrm{P}_{1}^{1}$ e, pelo algoritmo de De Casteljau, está na curva.

$\mathrm{P}_{0}^{2}(\mathrm{t})=(1-\mathrm{t}) \cdot\left(\mathrm{P}_{0}^{1}(\mathrm{t})\right)+\mathrm{t} \cdot\left(\mathrm{P}_{1}^{1}(\mathrm{t})\right)$ 


$$
\begin{aligned}
& P_{0}^{2}(t)=(1-t) \cdot\left((1-t) \cdot\left(P_{0}\right)+t \cdot\left(P_{1}\right)\right)+t\left((1-t) \cdot\left(P_{1}\right)+t \cdot\left(P_{2}\right)\right) \\
& P_{0}^{2}(t)=(1-t)^{2} \cdot\left(P_{0}\right)+2 t \cdot(1-t) \cdot\left(P_{1}\right)+t^{2}\left(P_{2}\right)
\end{aligned}
$$

Substituindo os pontos $\mathrm{P}_{0}, \mathrm{P}_{1}$ e $\mathrm{P}_{2}$ encontramos a equação paramétrica da curva:

$$
\begin{aligned}
& \mathrm{P}_{0}^{2}(\mathrm{t})=\left(1-2 \mathrm{t}+\mathrm{t}^{2}\right) \cdot\left(\begin{array}{c}
-1 \\
1
\end{array}\right)+\left(2 \mathrm{t}-2 \mathrm{t}^{2}\right) \cdot\left(\begin{array}{l}
0 \\
0
\end{array}\right)+\mathrm{t}^{2} \cdot\left(\begin{array}{l}
1 \\
1
\end{array}\right) \\
& \mathrm{P}_{0}^{2}(\mathrm{t})=\left(\begin{array}{c}
-1+2 \mathrm{t}-\mathrm{t}^{2}+\mathrm{t}^{2} \\
1-2 \mathrm{t}+\mathrm{t}^{2}+\mathrm{t}^{2}
\end{array}\right) \\
& \mathrm{P}_{0}^{2}(\mathrm{t})=\left(\begin{array}{c}
-1+2 \mathrm{t} \\
1-2 \mathrm{t}+2 \mathrm{t}^{2}
\end{array}\right)
\end{aligned}
$$

Fazendo t variar entre 0 e 1, obtemos a curva ilustrada na figura:

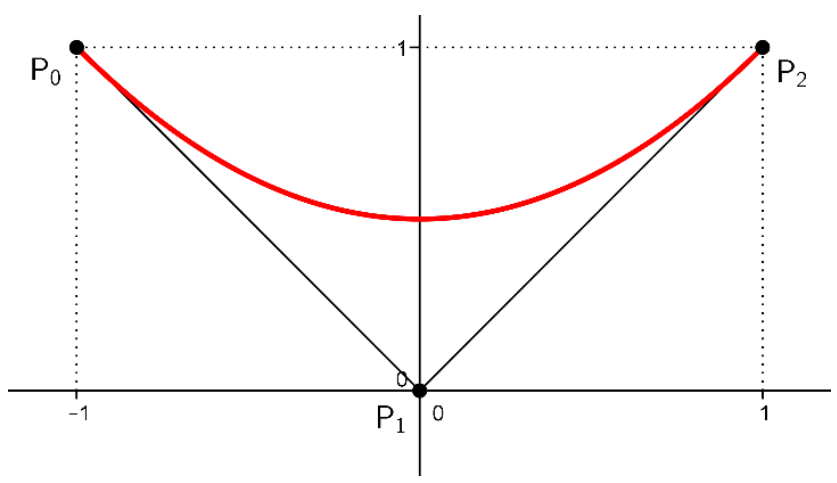

Figura 13: Curva de Bézier gerada pelos pontos $(1,1),(0,0)$ e $(1,1)$.

Exemplo 2: Encontrar a equação paramétrica da curva de Bézier gerada pelos pontos $(-1,1),(0,-1)$ e $(1,1)$.

Do exemplo anterior, temos que:

$P_{0}^{2}(t)=(1-t)^{2} \cdot\left(P_{0}\right)+2 t \cdot(1-t) \cdot\left(P_{1}\right)+t^{2}\left(P_{2}\right)$

Substituindo os pontos $\mathrm{P}_{0}, \mathrm{P}_{1}$ e $\mathrm{P}_{2}$ temos;

$$
\begin{aligned}
& P_{0}^{2}(t)=\left(1-2 t+t^{2}\right) \cdot\left(\begin{array}{c}
-1 \\
1
\end{array}\right)+\left(2 t-2 t^{2}\right) \cdot\left(\begin{array}{c}
0 \\
-1
\end{array}\right)+t^{2} \cdot\left(\begin{array}{l}
1 \\
1
\end{array}\right) \\
& P_{0}^{2}(t)=\left(\begin{array}{c}
-1+2 t-t^{2}+t^{2} \\
1-2 t+t^{2}-2 t+2 t^{2}+t^{2}
\end{array}\right)
\end{aligned}
$$




$$
\begin{aligned}
& \mathrm{P}_{0}^{2}(\mathrm{t})=\left(\begin{array}{c}
-1+2 \mathrm{t} \\
1-4 \mathrm{t}+4 \mathrm{t}^{2}
\end{array}\right) \\
& \mathrm{P}_{0}^{2}(\mathrm{t})=\left(\begin{array}{c}
-1+2 \mathrm{t} \\
(-1+2 \mathrm{t})^{2}
\end{array}\right) \boldsymbol{\square} \rightarrow \text { Equação paramétrica da curva } \mathrm{y}=\mathrm{x}^{2} \text {, veja a figura: }
\end{aligned}
$$

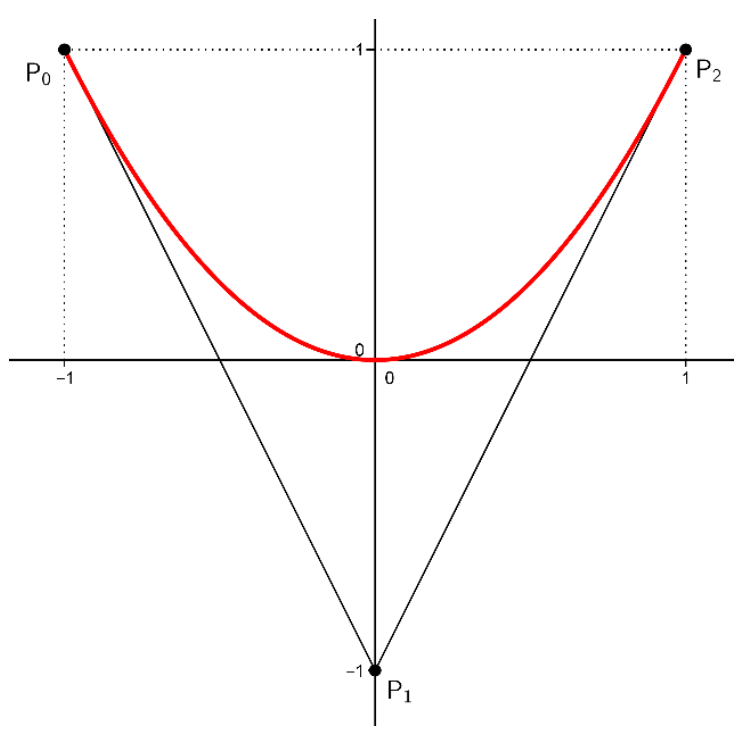

Figura 14: Curva de Bézier gerada pelos pontos $(-1,1),(0,-1)$ e $(1,1)$.

Nosso objetivo no próximo capítulo é apresentar curvas de Bézier restritas ao caso de gráfico de função.

Exemplo 3: Encontrar a equação paramétrica da curva de Bézier gerada pelos pontos $(1,1),(2,2)$ e $(3,1)$.

Do exemplo 1, temos que:

$P_{0}^{2}(t)=(1-t)^{2} \cdot\left(P_{0}\right)+2 t \cdot(1-t) \cdot\left(P_{1}\right)+t^{2}\left(P_{2}\right)$

Substituindo os pontos $\mathrm{P}_{0}, \mathrm{P}_{1}$ e $\mathrm{P}_{2}$ :

$$
\begin{aligned}
& \mathrm{P}_{0}^{2}(\mathrm{t})=\left(1-2 \mathrm{t}+\mathrm{t}^{2}\right) \cdot\left(\begin{array}{l}
1 \\
1
\end{array}\right)+\left(2 \mathrm{t}-2 \mathrm{t}^{2}\right) \cdot\left(\begin{array}{l}
2 \\
2
\end{array}\right)+\mathrm{t}^{2} \cdot\left(\begin{array}{l}
3 \\
1
\end{array}\right) \\
& \mathrm{P}_{0}^{2}(\mathrm{t})=\left(\begin{array}{c}
1-2 \mathrm{t}+\mathrm{t}^{2}+4 \mathrm{t}-4 \mathrm{t}^{2}+3 \mathrm{t}^{2} \\
1-2 \mathrm{t}+\mathrm{t}^{2}+4 \mathrm{t}-4 \mathrm{t}^{2}+\mathrm{t}^{2}
\end{array}\right) \\
& \mathrm{P}_{0}^{2}(\mathrm{t})=\left(\begin{array}{c}
1+2 \mathrm{t} \\
1+2 \mathrm{t}-2 \mathrm{t}^{2}
\end{array}\right) \quad \boldsymbol{\rightarrow} \rightarrow \text { Veja a parábola gerada: }
\end{aligned}
$$




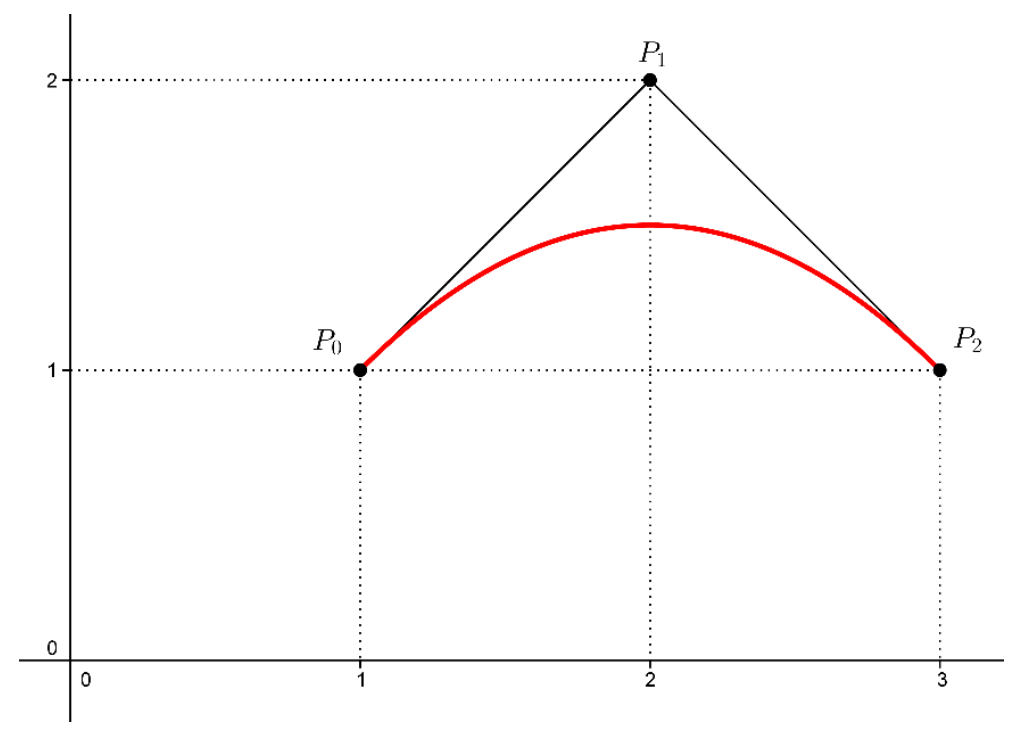

Figura 15: Curva de Bézier gerada pelos pontos $(1,1),(2,2)$ e $(3,1)$.

Exemplo 4: Generalizar a equação paramétrica da curva de Bézier gerada por 3 pontos $\mathrm{P}_{0}=\left(\mathrm{x}_{0}, \mathrm{y}_{\mathrm{o}}\right), \mathrm{P}_{1}=\left(\mathrm{x}_{1}, \mathrm{y}_{1}\right)$ e $\mathrm{P}_{2}=\left(\mathrm{x}_{2}, \mathrm{y}_{2}\right)$.

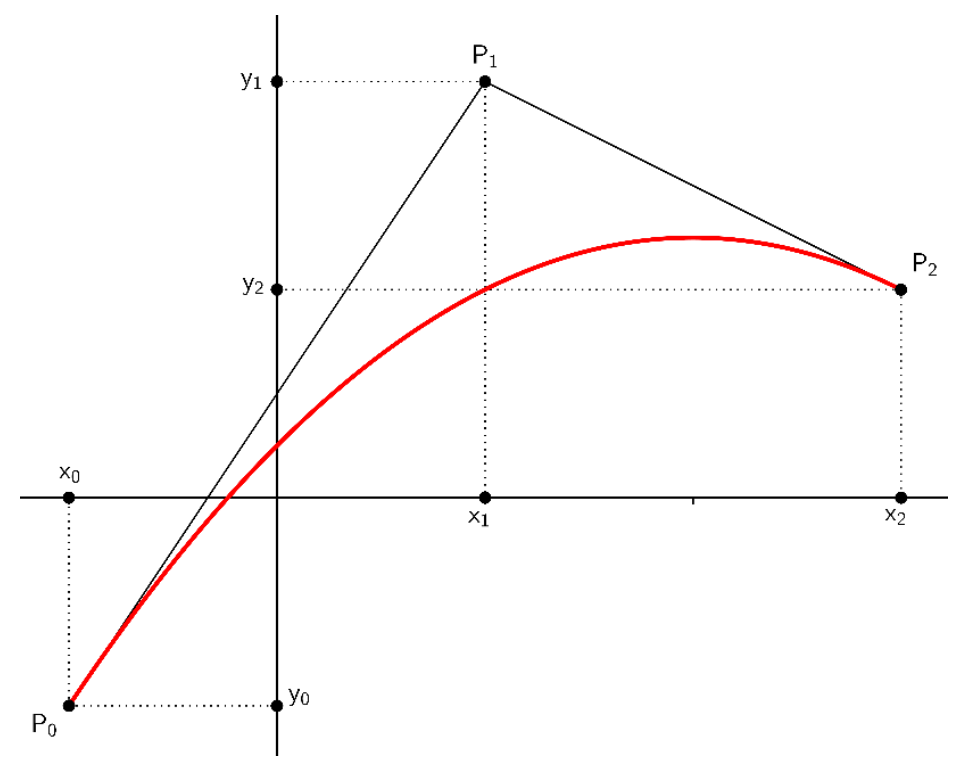

Figura 16: Generalização da curva de Bézier com 3 pontos de controle.

Do exemplo 1, temos que:

$P_{0}^{2}(t)=(1-t)^{2} \cdot\left(P_{0}\right)+2 t \cdot(1-t) \cdot\left(P_{1}\right)+t^{2}\left(P_{2}\right)$

Substituindo os pontos $\mathrm{P}_{0}, \mathrm{P}_{1}$ e $\mathrm{P}_{2}$ : 


$$
\begin{aligned}
& P_{0}^{2}(t)=(1-t)^{2} \cdot\left(\begin{array}{l}
x_{0} \\
y_{0}
\end{array}\right)+2 t \cdot(1-t) \cdot\left(\begin{array}{l}
x_{1} \\
y_{1}
\end{array}\right)+t^{2}\left(\begin{array}{l}
x_{2} \\
y_{2}
\end{array}\right) \\
& P_{0}^{2}(t)=\left(1-2 t+t^{2}\right) \cdot\left(\begin{array}{l}
x_{0} \\
y_{0}
\end{array}\right)+\left(2 t-2 t^{2}\right) \cdot\left(\begin{array}{l}
x_{1} \\
y_{1}
\end{array}\right)+t^{2} \cdot\left(\begin{array}{l}
x_{2} \\
y_{2}
\end{array}\right)
\end{aligned}
$$

Exemplo 5: Encontrar a equação paramétrica da curva de Bézier gerada pelos pontos de controle: $\mathrm{P}_{0}=\left(\mathrm{x}_{0}, \mathrm{y}_{\mathrm{o}}\right), \mathrm{P}_{1}=\left(\mathrm{x}_{1}, \mathrm{y}_{1}\right), \mathrm{P}_{2}=\left(\mathrm{x}_{2}, \mathrm{y}_{2}\right)$ e $\mathrm{P}_{3}=\left(\mathrm{x}_{3}, \mathrm{y}_{3}\right)$.

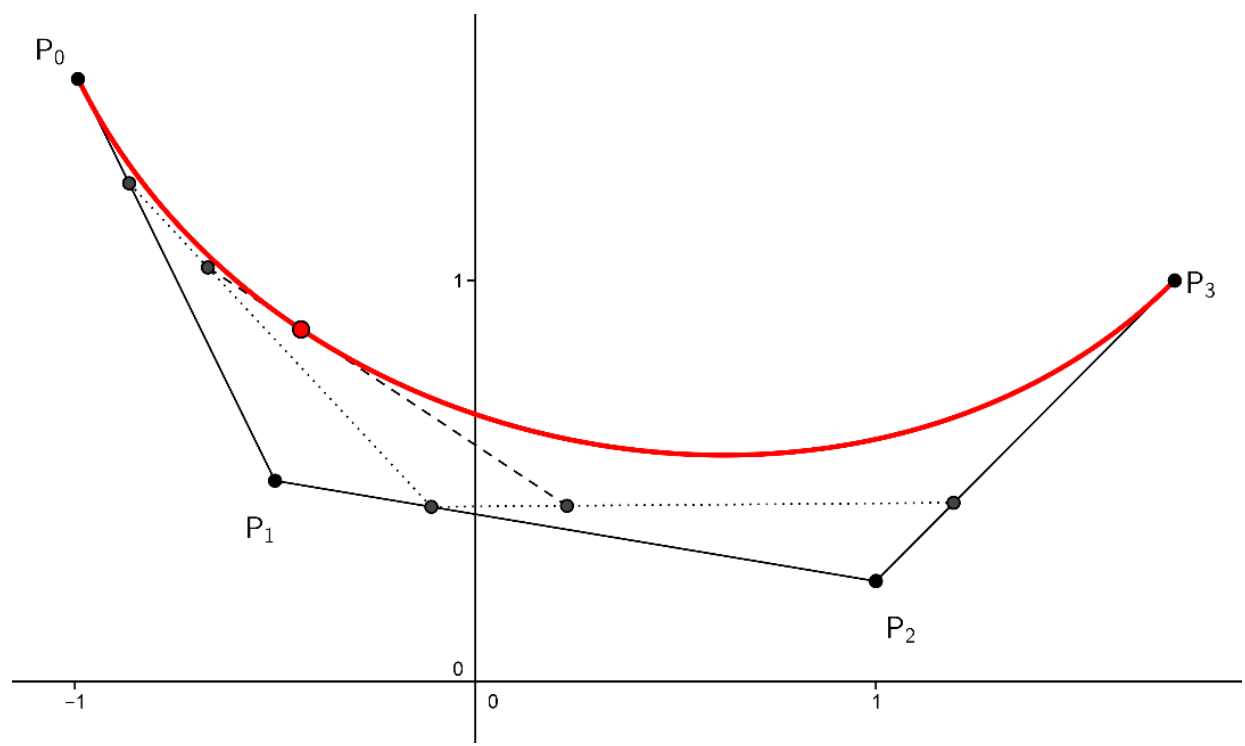

Figura 17: Generalização da curva de Bézier com 4 pontos de controle.

$$
\begin{aligned}
& P_{0}^{1}(t)=(1-t) \cdot\left(P_{0}\right)+t \cdot\left(P_{1}\right) \\
& P_{1}^{1}(t)=(1-t) \cdot\left(P_{1}\right)+t \cdot\left(P_{2}\right) \\
& P_{2}^{1}(t)=(1-t) \cdot\left(P_{2}\right)+t \cdot\left(P_{3}\right)
\end{aligned}
$$

$$
\begin{aligned}
& P_{0}^{2}(t)=(1-t) \cdot\left(P_{0}^{1}(t)\right)+t \cdot\left(P_{1}^{1}(t)\right) \\
& P_{0}^{2}(t)=(1-t) \cdot\left((1-t) \cdot\left(P_{0}\right)+t \cdot\left(P_{1}\right)\right)+t \cdot\left((1-t) \cdot\left(P_{1}\right)+t \cdot\left(P_{2}\right)\right) \\
& P_{0}^{2}(t)=(1-t)^{2} \cdot\left(P_{0}\right)+2 t \cdot(1-t) \cdot\left(P_{1}\right)+t^{2}\left(P_{2}\right)
\end{aligned}
$$

Analogamente:

$P_{1}^{2}(t)=(1-t)^{2} \cdot\left(P_{1}\right)+2 t \cdot(1-t) \cdot\left(P_{2}\right)+t^{2}\left(P_{3}\right)$

Então,

$$
\mathrm{P}_{0}^{3}(\mathrm{t})=(1-\mathrm{t}) \cdot\left(\mathrm{P}_{0}^{2}(\mathrm{t})\right)+\mathrm{t} \cdot\left(\mathrm{P}_{1}^{2}(\mathrm{t})\right)
$$




$$
\begin{aligned}
& \begin{aligned}
P_{0}^{3}(t)=(1-t) \cdot\left((1-t)^{2} \cdot\left(P_{0}\right)+2 t \cdot(1-t) \cdot\left(P_{1}\right)+t^{2}\left(P_{2}\right)\right)+t \cdot\left((1-t)^{2} \cdot\left(P_{1}\right)\right. \\
\left.+2 t \cdot(1-t) \cdot\left(P_{2}\right)+t^{2}\left(P_{3}\right)\right)
\end{aligned} \\
& \begin{aligned}
P_{0}^{3}(t)=(1-t)^{3} \cdot\left(P_{0}\right)+2 t \cdot(1-t)^{2} \cdot\left(P_{1}\right)+t^{2}(1-t) \cdot\left(P_{2}\right)+t(1-t)^{2} \cdot\left(P_{1}\right) \\
\quad+2 t^{2}(1-t) \cdot\left(P_{2}\right)+t^{3}\left(P_{3}\right)
\end{aligned} \\
& P_{0}^{3}(t)=(1-t)^{3} \cdot\left(P_{0}\right)+3 t \cdot(1-t)^{2} \cdot\left(P_{1}\right)+3 t^{2}(1-t) \cdot\left(P_{2}\right)+t^{3}\left(P_{3}\right)
\end{aligned}
$$




\section{Bézier não paramétrico}

A partir daqui vamos aplicar uma formulação restringindo a curva de Bézier, porém ainda podendo explorar suas propriedades, de tal forma que a curva represente o gráfico de uma função polinomial.

\section{1}

\section{Formulação não paramétrica}

Para obter uma formulação que seja o gráfico de uma função, ou seja, $y=$ $f(t)$, vamos usar a seguinte configuração: a coordenada $x$ do ponto de controle $P_{i}$ deve ser igual a $\frac{\mathrm{i}}{\mathrm{n}}$, onde os pontos de controle são $\mathrm{P}_{0}, \mathrm{P}_{1}, \ldots, \mathrm{P}_{\mathrm{n}}$. Considere, $\mathrm{P}_{0}=$ $\left(\mathrm{x}_{0}, \mathrm{y}_{\mathrm{o}}\right), \mathrm{P}_{1}=\left(\mathrm{x}_{1}, \mathrm{y}_{1}\right)$ e $\mathrm{P}_{2}=\left(\mathrm{x}_{2}, \mathrm{y}_{2}\right), 3$ pontos de controle. Quais os valores de $\mathrm{y}_{0}$, $y_{1}$ e $y_{2}$ nos fazem obter a curva $P(t)=\left(\begin{array}{c}t \\ t^{2}\end{array}\right)$, ou seja, a parábola? Nosso objetivo no caso geral é obter $\mathrm{x}(\mathrm{t})=\mathrm{t}$ e $\mathrm{y}(\mathrm{t})$ uma função polinomial.

Pela configuração acima, $x_{i}=\frac{i}{n}$, como queremos obter a parábola, $n=2$, logo:

- $\quad \mathrm{x}_{0}=\frac{0}{2}=0 \Rightarrow \mathrm{P}_{0}=\left(0, \mathrm{y}_{0}\right)$

- $\quad \mathrm{x}_{1}=\frac{1}{2} \Rightarrow \mathrm{P}_{1}=\left(\frac{1}{2}, \mathrm{y}_{1}\right)$

- $\quad \mathrm{x}_{2}=\frac{2}{2}=1 \Rightarrow \mathrm{P}_{2}=\left(1, \mathrm{y}_{2}\right)$

Vimos que a equação paramétrica da curva gerada por 3 pontos de controle é:

$P(t)=(1-t)^{2} \cdot\left(P_{0}\right)+2 t \cdot(1-t) \cdot\left(P_{1}\right)+t^{2}\left(P_{2}\right)$

Substituindo os pontos $\mathrm{P}_{0}=\left(0, \mathrm{y}_{0}\right), \mathrm{P}_{1}=\left(\frac{1}{2}, \mathrm{y}_{1}\right)$, e $\mathrm{P}_{2}=\left(1, \mathrm{y}_{2}\right)$ : 


$$
\begin{aligned}
& P(t)=(1-t)^{2} \cdot\left(\begin{array}{c}
0 \\
y_{0}
\end{array}\right)+2 t \cdot(1-t) \cdot\left(\begin{array}{c}
\frac{1}{2} \\
y_{1}
\end{array}\right)+t^{2}\left(\begin{array}{c}
1 \\
y_{2}
\end{array}\right) \\
& P(t)=\left(1-2 t+t^{2}\right) \cdot\left(\begin{array}{c}
0 \\
y_{0}
\end{array}\right)+\left(2 t-2 t^{2}\right) \cdot\left(\begin{array}{c}
\frac{1}{2} \\
y_{1}
\end{array}\right)+t^{2} \cdot\left(\begin{array}{c}
1 \\
y_{2}
\end{array}\right) \\
& P(t)=\left(\begin{array}{c}
t-t^{2}+t^{2} \\
y_{0}-2 t y_{0}+t^{2} y_{0}+2 t y_{1}-2 t^{2} y_{1}+t^{2} y_{2}
\end{array}\right) \\
& P(t)=\left(\begin{array}{c}
t \\
y_{0}-2 t\left(y_{0}-y_{1}\right)+t^{2}\left(y_{0}-2 y_{1}+y_{2}\right)
\end{array}\right)
\end{aligned}
$$

Para obtermos, $P(t)=\left(\begin{array}{c}t \\ t^{2}\end{array}\right)$, basta resolvermos o seguinte sistema:

$$
\left\{\begin{array} { c } 
{ \mathrm { y } _ { 0 } = 0 } \\
{ \mathrm { y } _ { 0 } - \mathrm { y } _ { 1 } = 0 } \\
{ \mathrm { y } _ { 0 } - 2 \mathrm { y } _ { 1 } + \mathrm { y } _ { 2 } = 1 }
\end{array} \Rightarrow \left\{\begin{array}{l}
\mathrm{y}_{0}=0 \\
\mathrm{y}_{1}=0 \\
\mathrm{y}_{2}=1
\end{array}\right.\right.
$$

Portanto os pontos são: $P_{0}=(0,0), P_{1}=\left(\frac{1}{2}, 0\right), P_{2}=(1,1)$. Veja a figura:

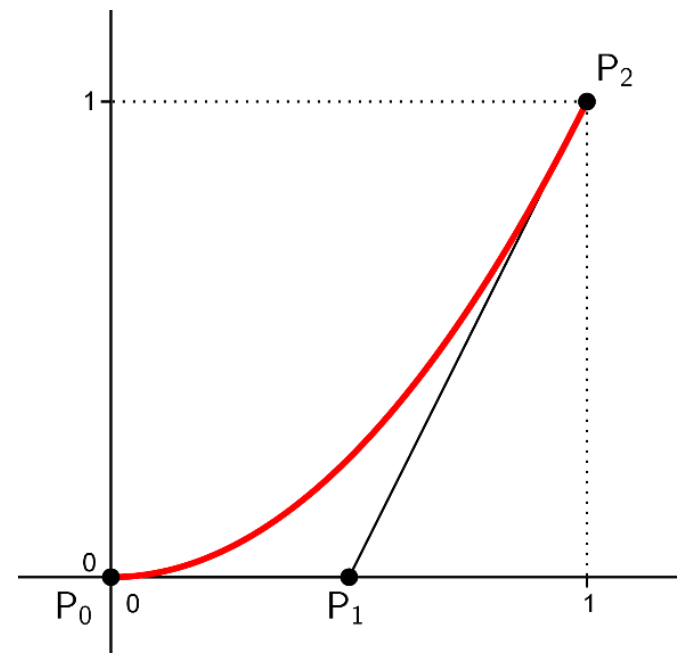

Figura 18: Gráfico da função $y(t)=t^{2}$.

Vamos verificar que ao considerarmos $x_{i}=\frac{i}{n}$, obteremos $x(t)=t$. Partindo da formulação de Bézier:

$$
B(t)=\sum_{i=0}^{n} P_{i}\left(\begin{array}{l}
n \\
i
\end{array}\right)(1-t)^{n-i_{1} i}
$$


Observe pelo binômio de Newton que:

$$
(x+a)^{n}=\sum_{i=0}^{n}\left(\begin{array}{l}
n \\
i
\end{array}\right) x^{n} a^{n-i}
$$

Logo,

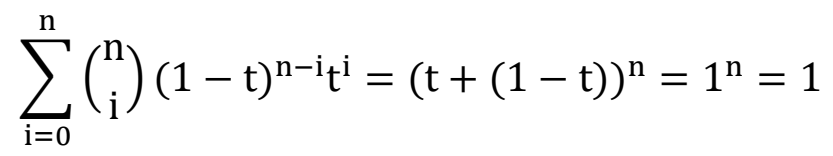

Agora para $P_{i}=\frac{i}{n}$ segue que:

$$
\begin{aligned}
& \sum_{i=0}^{n} \frac{i}{n}\left(\begin{array}{l}
n \\
i
\end{array}\right)(1-t)^{n-i} t^{i}=\sum_{i=0}^{n} \frac{i}{n} \frac{n !}{i !(n-i) !}(1-t)^{n-i_{1}} t^{i}= \\
= & \sum_{i=0}^{n} \frac{(n-1) !}{(i-1) !(n-i) !}(1-t)^{n-i} t^{i}=\sum_{i=0}^{n}\left(\begin{array}{c}
n-1 \\
i-1
\end{array}\right)(1-t)^{n-i} t^{i}= \\
= & \sum_{i=0}^{n}\left(\begin{array}{l}
n-1 \\
i-1
\end{array}\right)(1-t)^{n-i} t^{i-1}=t \sum_{i=0}^{n}\left(\begin{array}{c}
n-1 \\
i-1
\end{array}\right)(1-t)^{n-i} t^{i-1}= \\
= & t \sum_{i=0}^{n}\left(\begin{array}{c}
n-1 \\
i-1
\end{array}\right)(1-t)^{(n-1)-(i-1)} t^{i-1}=t(t+(1-t))^{n-1}=t
\end{aligned}
$$

Com esta formulação, acabamos perdendo flexibilidade para modelagem, porque os pontos deixam de ser livres e se tornam semi livres, ou seja, a coordenada t está fixa podendo variar apenas a coordenada y do ponto de controle. Mas as propriedades da curva de Bézier continuam válidas.

Vejamos alguns exemplos:

Exemplo 1: Sejam, $P_{0}=\left(x_{0}, y_{0}\right), P_{1}=\left(x_{1}, y_{1}\right), P_{2}=\left(x_{2}, y_{2}\right)$ e $P_{3}=$ $\left(\mathrm{x}_{3}, \mathrm{y}_{3}\right) 4$ pontos de controle. Vamos usar a seguinte configuração: $\mathrm{x}_{\mathrm{i}}=\frac{\mathrm{i}}{\mathrm{n}}$, com $\mathrm{n}=$ 3. Quais os valores de $y_{0}, y_{1}, y_{2}$ e $y_{3}$ nos fazem obter a curva $P(t)=\left(\begin{array}{c}t \\ t^{3}\end{array}\right)$ ?

Pela configuração acima, temos que: 
- $\quad \mathrm{x}_{0}=\frac{0}{3}=0 \Rightarrow \mathrm{P}_{0}=\left(0, \mathrm{y}_{0}\right)$

- $\quad \mathrm{x}_{1}=\frac{1}{3} \Rightarrow \mathrm{P}_{1}=\left(\frac{1}{3}, \mathrm{y}_{1}\right)$

- $\quad \mathrm{x}_{2}=\frac{2}{3} \Rightarrow \mathrm{P}_{2}=\left(\frac{2}{3}, \mathrm{y}_{2}\right)$

- $\mathrm{x}_{3}=\frac{3}{3}=1 \Rightarrow \mathrm{P}_{3}=\left(1, \mathrm{y}_{3}\right)$

Vimos, no exemplo 5, que a equação paramétrica da curva gerada por 4 pontos de controle é:

$P(t)=(1-t)^{3} \cdot\left(P_{0}\right)+3 t \cdot(1-t)^{2} \cdot\left(P_{1}\right)+3 t^{2}(1-t) \cdot\left(P_{2}\right)+t^{3}\left(P_{3}\right)$

Substituindo os pontos $\mathrm{P}_{0}=\left(0, \mathrm{y}_{0}\right), \mathrm{P}_{1}=\left(\frac{1}{3}, \mathrm{y}_{1}\right), \mathrm{P}_{2}=\left(\frac{2}{3}, \mathrm{y}_{2}\right)$ e $\mathrm{P}_{3}=$ $\left(1, y_{3}\right)$ obtemos a curva:

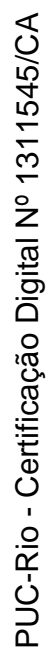

$$
\begin{gathered}
P(t)=(1-t)^{3} \cdot\left(\frac{0}{y_{0}}\right)+3 t \cdot(1-t)^{2} \cdot\left(\frac{\frac{1}{3}}{y_{1}}\right)+3 t^{2}(1-t) \cdot\left(\frac{\frac{2}{3}}{y_{2}}\right)+t^{3}\left(\frac{1}{y_{3}}\right) \\
P(t)=\left(1-3 t+3 t^{2}-t^{3}\right)\left(\frac{0}{y_{0}}\right)+\left(3 t-6 t^{2}+3 t^{3}\right)\left(\frac{\frac{1}{3}}{y_{1}}\right)+\left(3 t^{2}-3 t^{3}\right)\left(\frac{\frac{2}{3}}{y_{2}}\right) \\
+t^{3}\left(\frac{1}{y_{3}}\right)
\end{gathered}
$$

$P(t)$

$$
\begin{aligned}
& =\left(\begin{array}{c}
t-2 t^{2}+t^{3}+2 t^{2}-t^{3} \\
y_{0}-3 t y_{0}+3 t^{2} y_{0}-t^{3} y_{0}+3 t y_{1}-6 t^{2} y_{1}+3 t^{3} y_{1}+3 t^{2} y_{2}-3 t^{3} y_{2}+t^{3} y_{3}
\end{array}\right) \\
& P(t)=\left(\begin{array}{c}
t \\
y_{0}-3 t\left(y_{0}-y_{1}\right)+3 t^{2}\left(y_{0}-2 y_{1}+y_{2}\right)-t^{3}\left(y_{0}-3 y_{1}+3 y_{2}-y_{3}\right)
\end{array}\right)
\end{aligned}
$$

Queremos $P(t)=\left(\begin{array}{c}t \\ t^{3}\end{array}\right)$, para isso vamos resolver o seguinte sistema:

$$
\left\{\begin{array} { c } 
{ y _ { 0 } = 0 } \\
{ y _ { 0 } - y _ { 1 } = 0 } \\
{ y _ { 0 } - 2 y _ { 1 } + y _ { 2 } = 0 } \\
{ y _ { 0 } - 3 y _ { 1 } + 3 y _ { 2 } - y _ { 3 } = - 1 }
\end{array} \Longrightarrow \left\{\begin{array}{l}
\mathrm{y}_{0}=0 \\
\mathrm{y}_{1}=0 \\
\mathrm{y}_{2}=0 \\
\mathrm{y}_{3}=1
\end{array}\right.\right.
$$


Portanto os pontos são: $\mathrm{P}_{0}=(0,0), \mathrm{P}_{1}=\left(\frac{1}{3}, 0\right), \mathrm{P}_{2}=\left(\frac{2}{3}, 0\right)$ e $\mathrm{P}_{3}=(1,1)$.

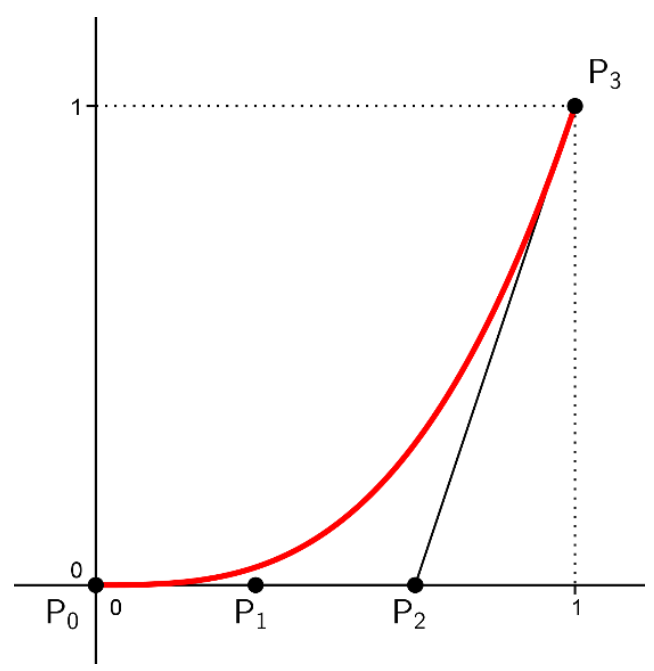

Figura 19: Gráfico da função $y(t)=t^{3}$

Exemplo 2: Sejam os pontos $\mathrm{P}_{0}=\left(0, \mathrm{y}_{0}\right), \mathrm{P}_{1}=\left(\frac{1}{3}, \mathrm{y}_{1}\right), \mathrm{P}_{2}=\left(\frac{2}{3}, \mathrm{y}_{2}\right)$ e $\mathrm{P}_{3}=$ $\left(1, y_{3}\right)$ obtidos através da configuração do exemplo anterior. Vamos encontrar as coordenadas $\mathrm{y}_{0}, \mathrm{y}_{1}, \mathrm{y}_{2}$ e $\mathrm{y}_{3}$ para que o polinômio encontrado seja $\mathrm{y}(\mathrm{t})=-3 \mathrm{t}^{3}+$ $\frac{9}{2} \mathrm{t}^{2}-\frac{1}{2} \mathrm{t}$

Substituindo esses pontos na equação paramétrica, obtivemos:

$$
P(t)=\left(y_{0}-3 t\left(y_{0}-y_{1}\right)+3 t^{2}\left(y_{0}-2 y_{1}+y_{2}\right)-t^{3}\left(y_{0}-3 y_{1}+3 y_{2}-y_{3}\right)\right)
$$

Para encontramos o polinômio $\mathrm{y}(\mathrm{t})=-3 \mathrm{t}^{3}+\frac{9}{2} \mathrm{t}^{2}-\frac{1}{2} \mathrm{t}$, vamos resolver o seguinte sistema:

$$
\left\{\begin{array} { c } 
{ y _ { 0 } = 0 } \\
{ 3 ( y _ { 0 } - y _ { 1 } ) = \frac { 1 } { 2 } } \\
{ 3 ( y _ { 0 } - 2 y _ { 1 } + y _ { 2 } ) = \frac { 9 } { 2 } } \\
{ y _ { 0 } - 3 y _ { 1 } + 3 y _ { 2 } - y _ { 3 } = 3 }
\end{array} \Rightarrow \left\{\begin{array}{c}
\mathrm{y}_{0}=0 \\
\mathrm{y}_{1}=-\frac{1}{6} \\
\mathrm{y}_{2}=\frac{7}{6} \\
\mathrm{y}_{3}=1
\end{array}\right.\right.
$$

Logo, os pontos são: $P_{0}=(0,0), P_{1}=\left(\frac{1}{3},-\frac{1}{6}\right), P_{2}=\left(\frac{2}{3}, \frac{7}{6}\right)$ e $P_{3}=(1,1)$. 


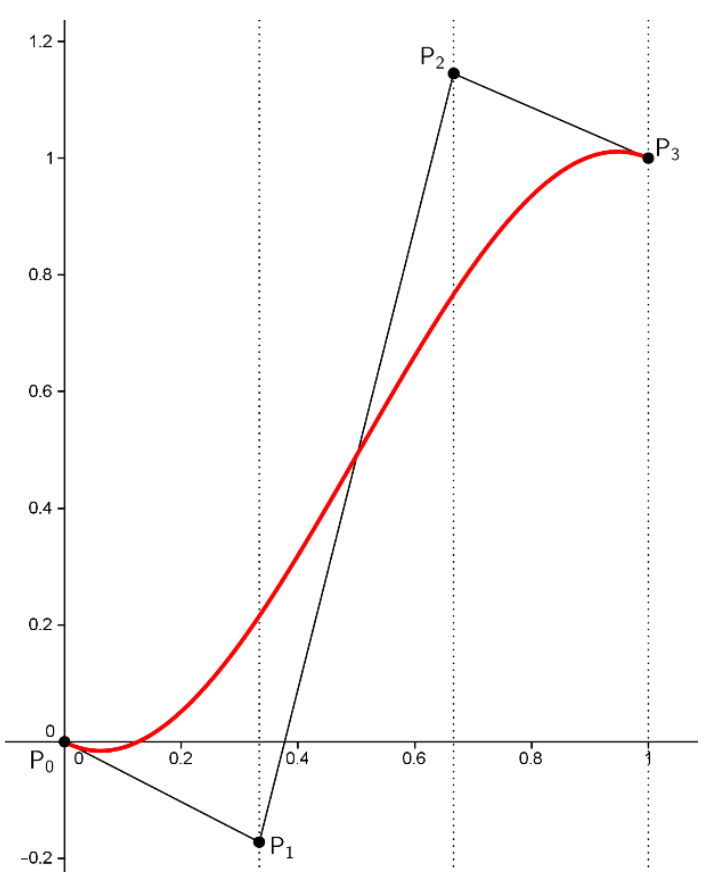

Figura 20: Gráfico do polinômio $y(t)=-3 t^{3}+\frac{9}{2} t^{2}-\frac{1}{2} t$.

Entre as propriedades interessantes que nós temos a nossa disposição, embora restritas, está a capacidade de modelar e construir um polinômio usando os pontos de controle, de tal forma que possamos reproduzir aproximadamente uma curva desejada. 


\section{Resultado em Sala de Aula}

As atividades propostas na oficina em sala de aula foram produzidas no software Geogebra 5, usando o algoritmo de De Casteljau (veremos mais a frente). Além do conteúdo computacional, foi construído um aparato manual com madeira e elásticos, que representa uma curva de De Casteljau, veja figura 21.
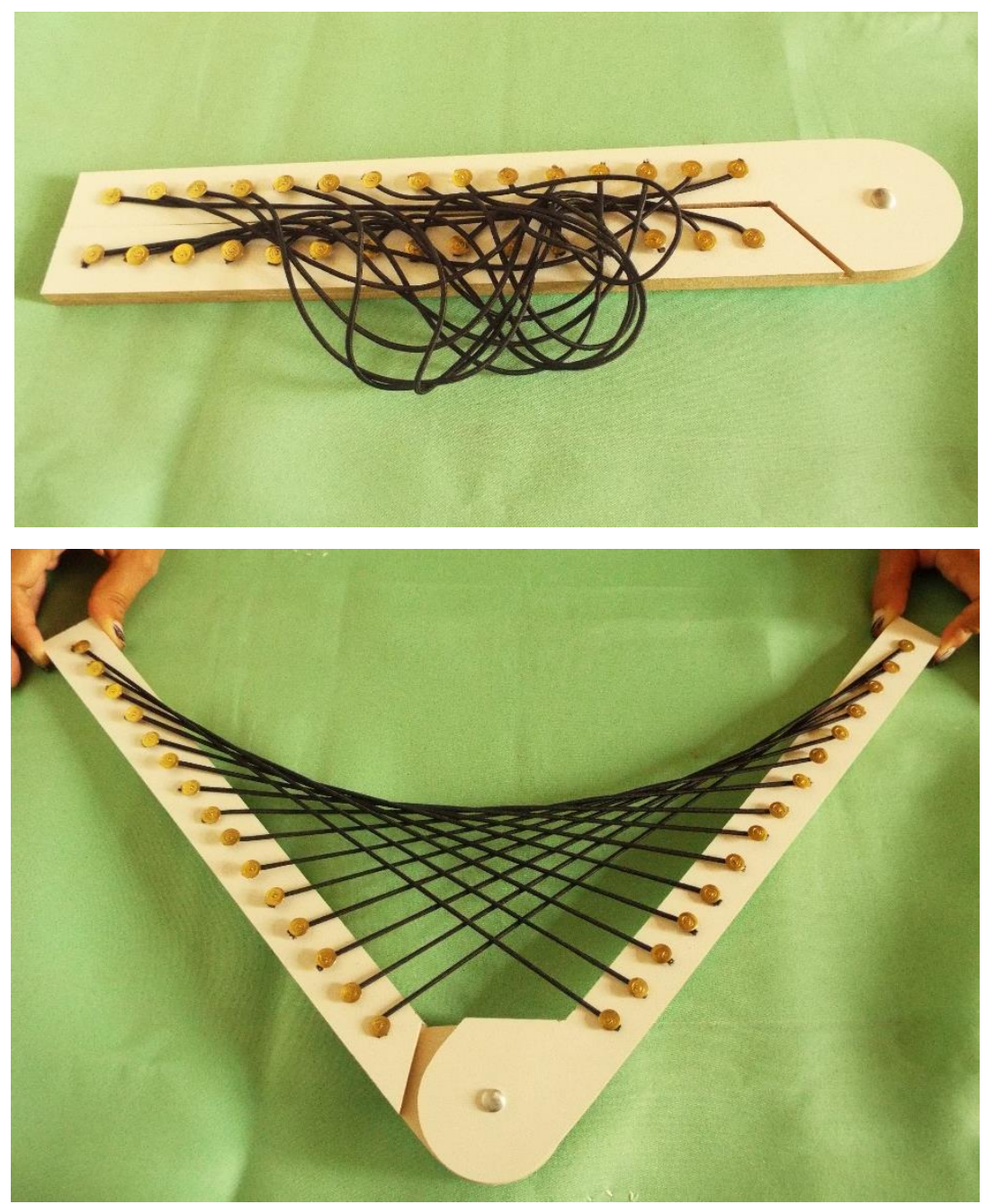

Figura 21: Aparato de madeira e elástico, construído para descrever o algoritmo de De Casteljau.

A proposta inicial para essa oficina era de realizá-la com dois grupos, um com 5 alunos do $9^{\circ}$ ano do ensino fundamental e outro com 5 alunos do $2^{\circ}$ ano do ensino médio. Mas devido a problemas na unidade escolar, os alunos do $9^{\circ}$ ano foram dispensados mais cedo e apenas um dos 5 alunos dessa turma retornou, no horário combinado, para a oficina. 
Apesar do contratempo, a oficina foi realizada no dia 14 de dezembro de 2014, no laboratório de informática do CIEP 306 Dep. David Quinderê, com 5 alunos do $2^{\circ}$ ano do ensino médio e 1 aluno do $9^{\circ}$ ano do ensino fundamental. Os alunos receberam: um questionário contendo todas as atividades da oficina (Anexo 1); uma ficha de auto avaliação (Anexo 2); lápis, régua e papel A4 para preencher as folhas e rascunhar. Veja na figura 22 algumas fotos da oficina.

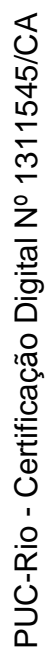

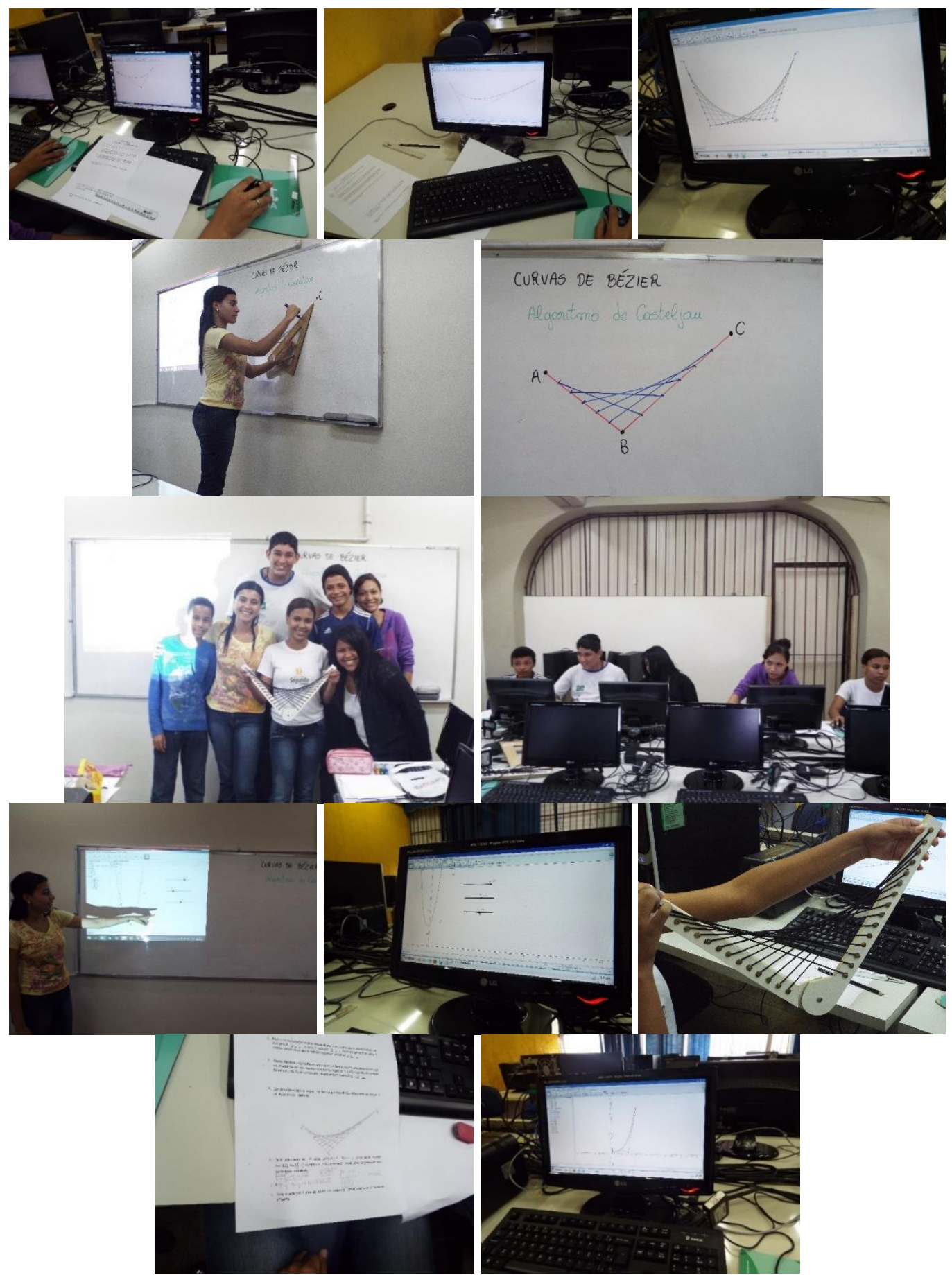

Figura 22: Fotos da Oficina. 
Toda experiência teve duração aproximada de duas horas, iniciando com uma apresentação breve da curva de Bézier e do algoritmo de De Casteljau. Os alunos aprenderam alguns comandos básicos do Geogebra e manusearam duas curvas construídas com o algoritmo. Logo após, a primeira atividade foi explicada e os alunos tiveram em torno de 10 minutos para responder e trocar informações. Ao final desse tempo a questão era discutida e esclarecida. Uma nova atividade era sugerida, e assim por diante.

Veremos como foram produzidas e qual(is) o(s) objetivo(s) de cada atividade.

Para construir todos os modelos, no Geogebra, usaremos: a ferramenta "ponto" para criar os pontos de controle, a ferramenta "segmento" para criar os segmentos e a ferramenta "lugar geométrico" para desenhar a curva.

Nas duas primeiras atividades vamos mostrar dois modos diferentes de obter a curva.

$\mathbf{1}^{\text {a }}$ Atividade: Casteljau 3 pontos de controle

Primeiramente criamos 3 pontos, A, B e C, depois os segmentos $\mathrm{AB}$ e $\mathrm{BC}$. Marcamos um ponto $\mathrm{P}$ sobre o segmento AB. Vamos utilizar o campo de entrada para calcular a razão: $\mathrm{t}=\operatorname{Distância}[\mathrm{A}, \mathrm{P}] /$ Distância $[\mathrm{A}, \mathrm{B}]$, após encontrar esse número vamos usar o algoritmo de De Casteljau, já visto, para parametrizar os outros segmentos. Ainda no campo de entrada digitamos: $\mathrm{Q}=(1-\mathrm{t}) * \mathrm{~B}+\mathrm{t} * \mathrm{C}$, surgindo o ponto Q. Analogamente, criamos o ponto O. Restando apenas usar a ferramenta "Lugar Geométrico" do ponto O conforme P varia, encontrando assim a curva desejada. 


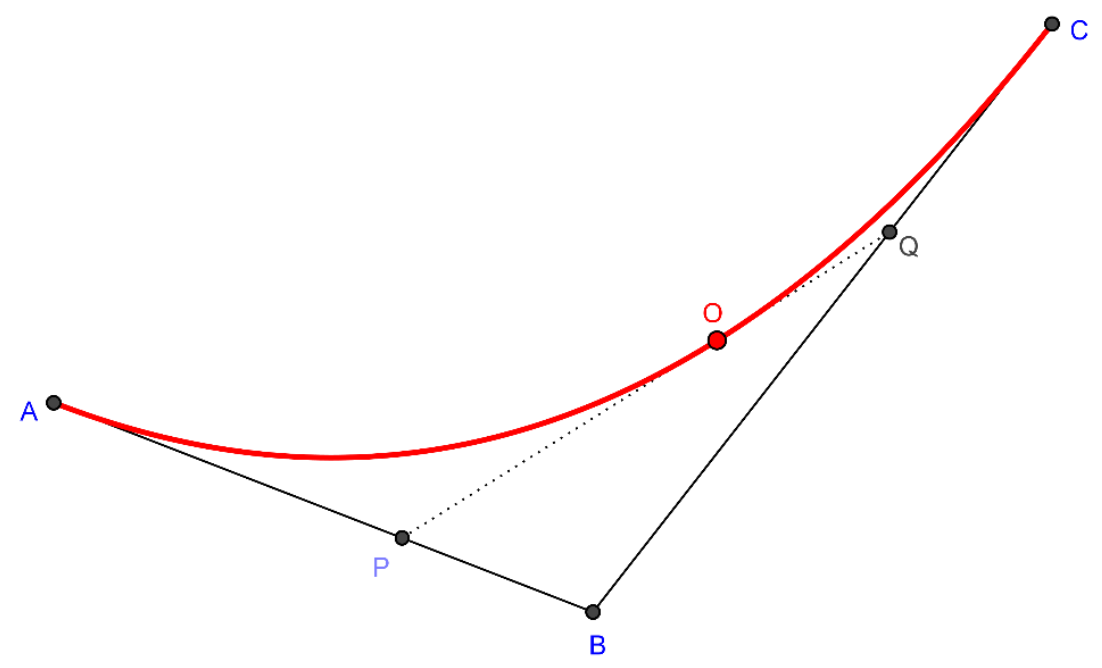

Figura 23: Algoritmo de De Casteljau com 3 pontos de controle.

O objetivo dessa atividade é mostrar ao aluno que para quaisquer pontos $\mathrm{A}$, $\mathrm{B}$ e $\mathrm{C}$ o ponto $\mathrm{O}$ vai sempre pertencer a curva. Comprovando assim a eficácia do algoritmo.

$\mathbf{2}^{\mathrm{a}}$ Atividade: Casteljau 4 pontos de controle:

Criamos os pontos A, B, C, D e os segmentos AB, BC e CD. Com a ferramenta "Controle Deslizante", vamos criar um número $t \in[0,1]$. Usando o campo de entrada do Geogebra, iremos parametrizar os segmentos. Para o ponto E:

\section{Entrada: $E=(1-1)^{\star} A+{ }^{\star} B$}

Figura 24: Campo de entrada: parametrização de um segmento.

E assim por diante até obtermos o ponto J. Daí bastar construirmos o lugar geométrico do ponto $\mathrm{J}$ conforme $\mathrm{t}$ varia. 


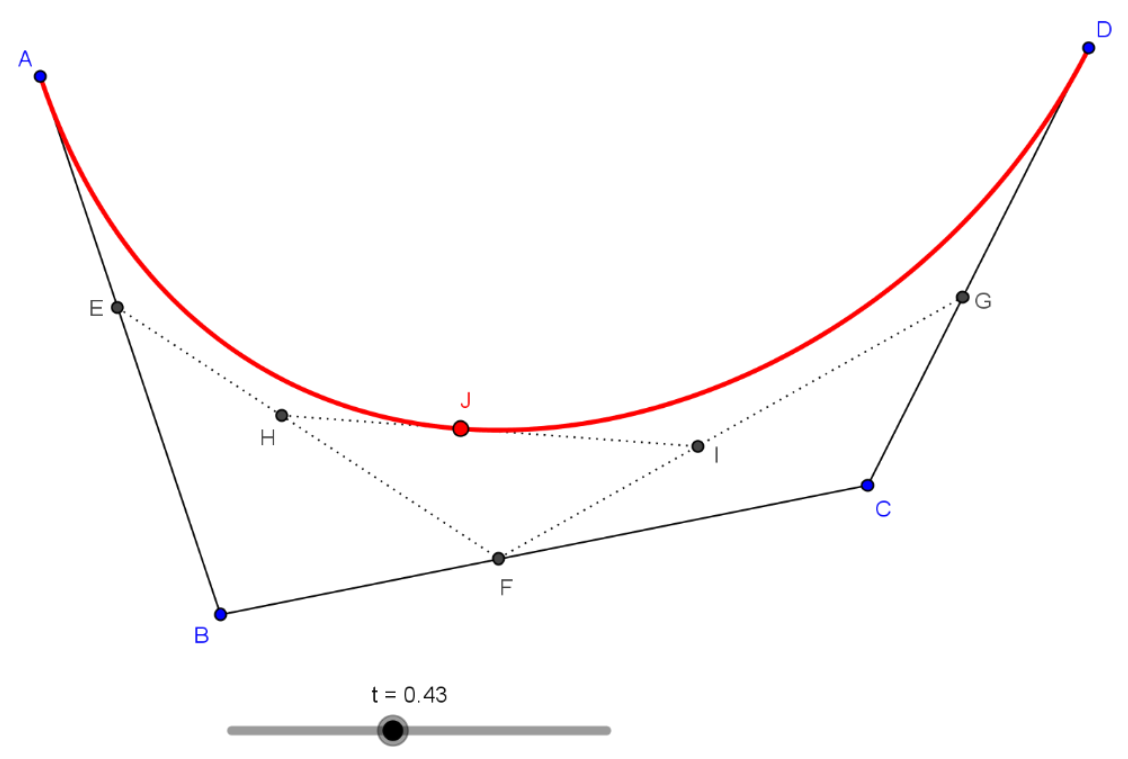

Figura 25: Algoritmo de De Casteljau com 4 pontos de controle.

Esse é outro exemplo do algoritmo, porém com 4 pontos de controle. Aqui o aluno já pode associar o número de pontos de controle com o grau da curva, ou seja, com 4 pontos de controle a curva terá grau máximo 3 (Anexo 3 - Atividade 1 e 2).

$3^{\mathbf{a}}$ Atividade: Divisão em 10 partes iguais.

Para fazermos a construção dessa curva, vamos criar 4 pontos A, B, C e D e os segmentos AB, BC e CD. Não utilizaremos o parâmetro t, faremos uma construção "livre" usando os números 0,$1 ; 0,2 ; \ldots ; 0,9$ e a definição de parametrização. Para obtermos os pontos E e F, por exemplo, faremos assim:

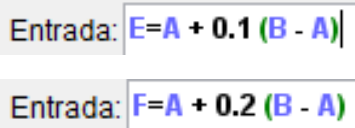

Figura 26: Campo de entrada: divisão do segmento em 10 partes iguais.

Analogamente vamos encontrar os pontos sobre os segmentos, restando apenas unir os respectivos pontos. $\mathrm{O}$ ponto $\mathrm{E}$ ao ponto $\mathrm{N}$, o ponto $\mathrm{F}$ ao ponto $\mathrm{O}, \ldots$, o ponto $\mathrm{N}$ ao $\mathrm{W}$, o ponto $\mathrm{O}$ ao $\mathrm{Z}, \ldots$ e assim encontraremos nossa curva. 


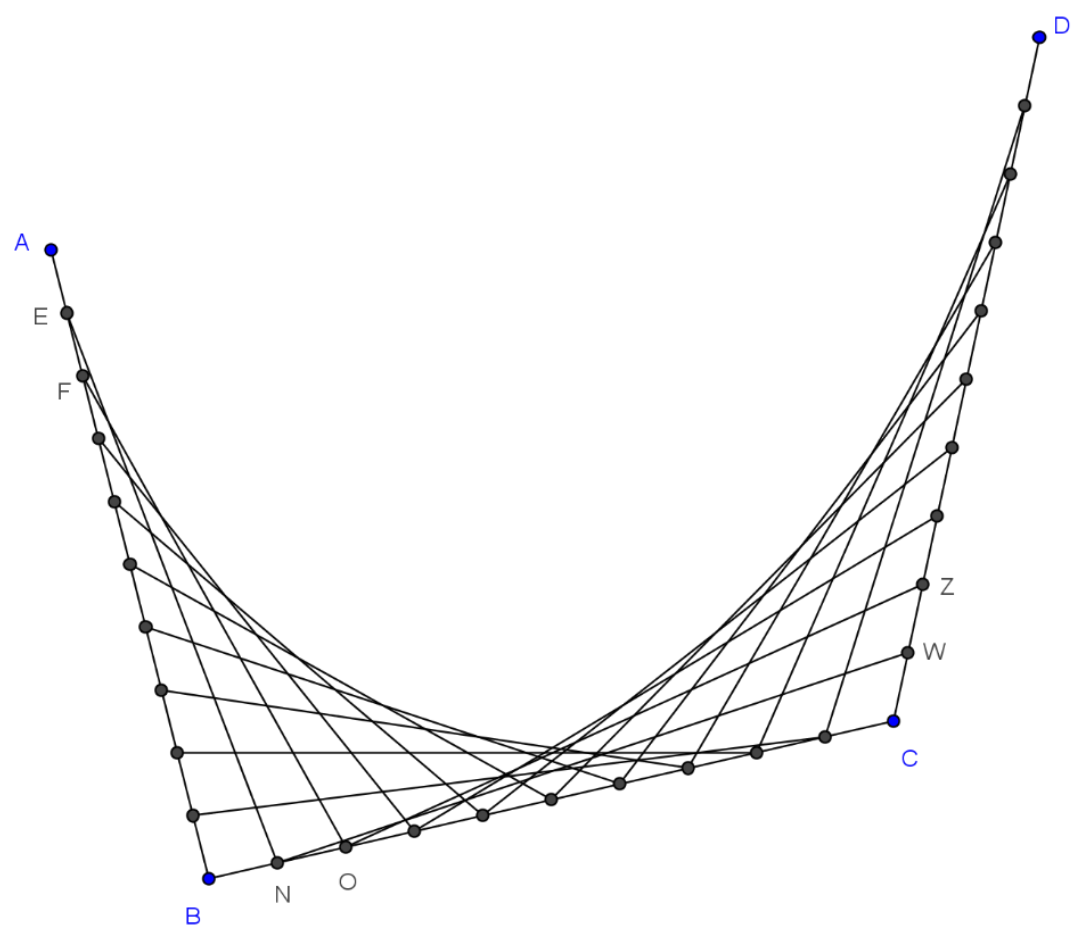

Figura 27: Algoritmo de De Casteljau, construção livre.

O objetivo desta atividade é fazer com que os alunos produzam suas próprias curvas, usando apenas lápis, régua e papel. Sem a necessidade de fazer cálculo (Anexo 3 - Atividade 3).

4a Atividade: Bézier não paramétrico

Nessa atividade estamos reproduzindo os exemplos 1 e 2 do capítulo 3.

Essa construção é análoga a $\mathbf{2}^{\mathbf{a}}$ atividade, porém os pontos A, B, C e D foram construídos sobre as retas $x=0, x=\frac{1}{3}, x=\frac{2}{3}$ e $x=1$, respectivamente.

Para descobrirmos a função que essa curva descreve, vamos usar a formulação já vista na página $31, P(\mathrm{x})=\mathrm{y}_{0}-3 \mathrm{x}\left(\mathrm{y}_{0}-\mathrm{y}_{1}\right)+3 x^{2}\left(\mathrm{y}_{0}-2 \mathrm{y}_{1}+\mathrm{y}_{2}\right)-$ $\mathrm{x}^{3}\left(\mathrm{y}_{0}-3 \mathrm{y}_{1}+3 \mathrm{y}_{2}-\mathrm{y}_{3}\right)$, onde $\mathrm{y}_{0}$ é a ordenada do ponto $\mathrm{A}, \mathrm{y}_{1}$ é a ordenada do ponto $\mathrm{B}, \mathrm{y}_{2}$ é a ordenada do ponto $\mathrm{C}$ e $\mathrm{y}_{3}$ é a ordenada do ponto $\mathrm{D}$. Para encontrar a expressão simplificada usamos a ferramenta "Calcular Valor Numérico", da janela CAS. 


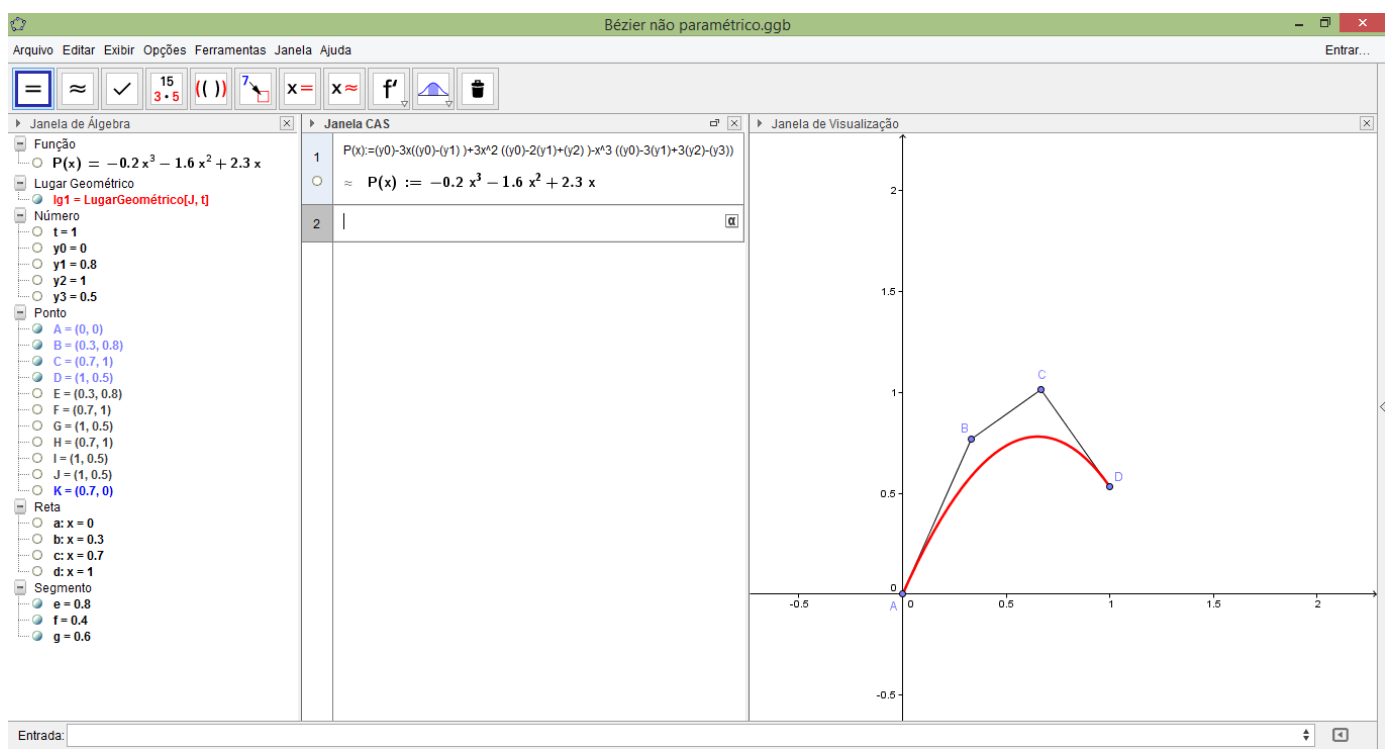

Figura 28: Bézier não paramétrico, janela CAS mostrando a formulação polinomial.

A proposta dessa atividade é mostrar que com esses pontos, podemos encontrar um pedaço de qualquer polinômio de grau menor ou igual a 3. O desafio dos alunos era encontrar os pontos de controle que geram a curva $\mathrm{P}(\mathrm{x})=\mathrm{x}^{3}$. A verificação podia ser feita através da janela de álgebra (Anexo 3 - Atividade Computacional 1).

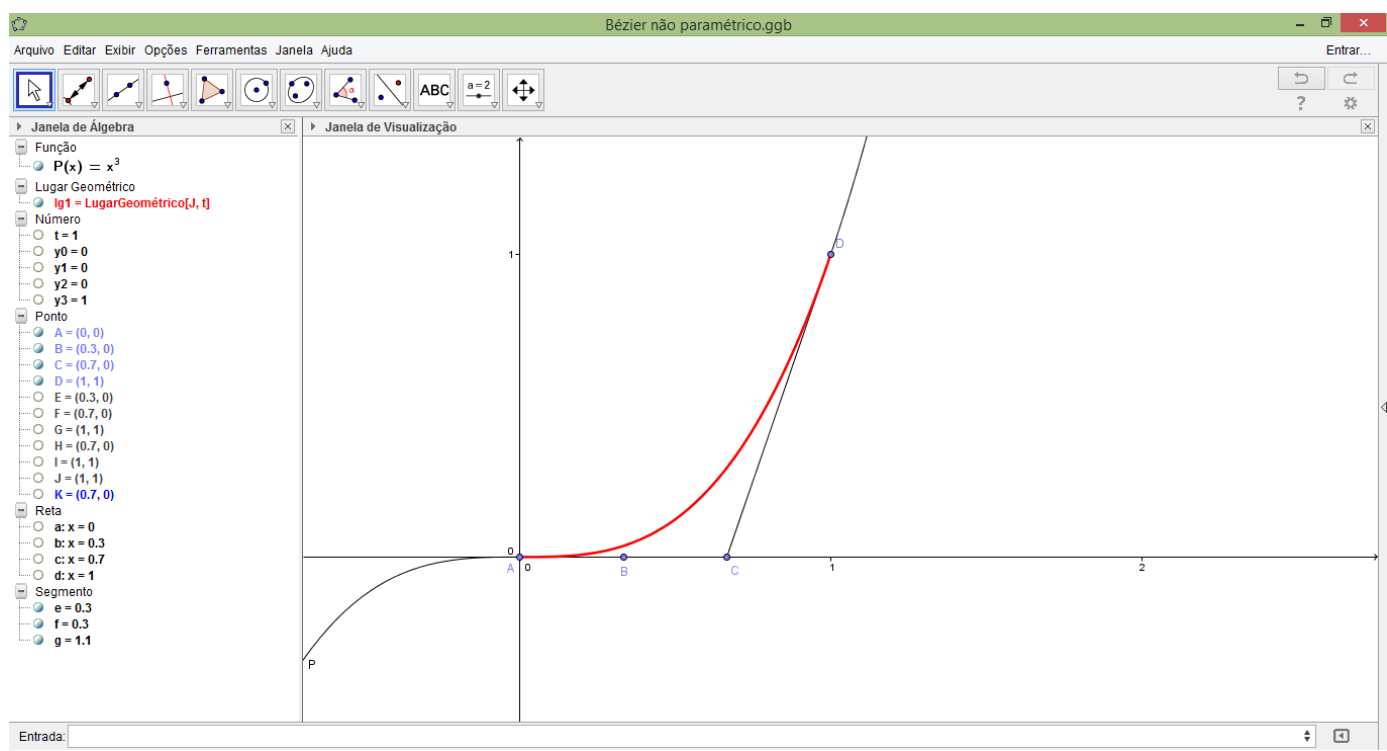

Figura 29: Bézier não paramétrico, janela visualização mostrando a curva de Bézier e o gráfico da função $f(x)=x^{3}$. 
Para essa construção, se faz necessário alguns ajustes com relação ao número de casas decimais. Para algumas curvas, uma ou duas casas decimais não são suficientes para determinar com exatidão o gráfico da função. No menu "opções" podemos arredondar até 15 casas decimais. Observe as figuras 30 e 31.

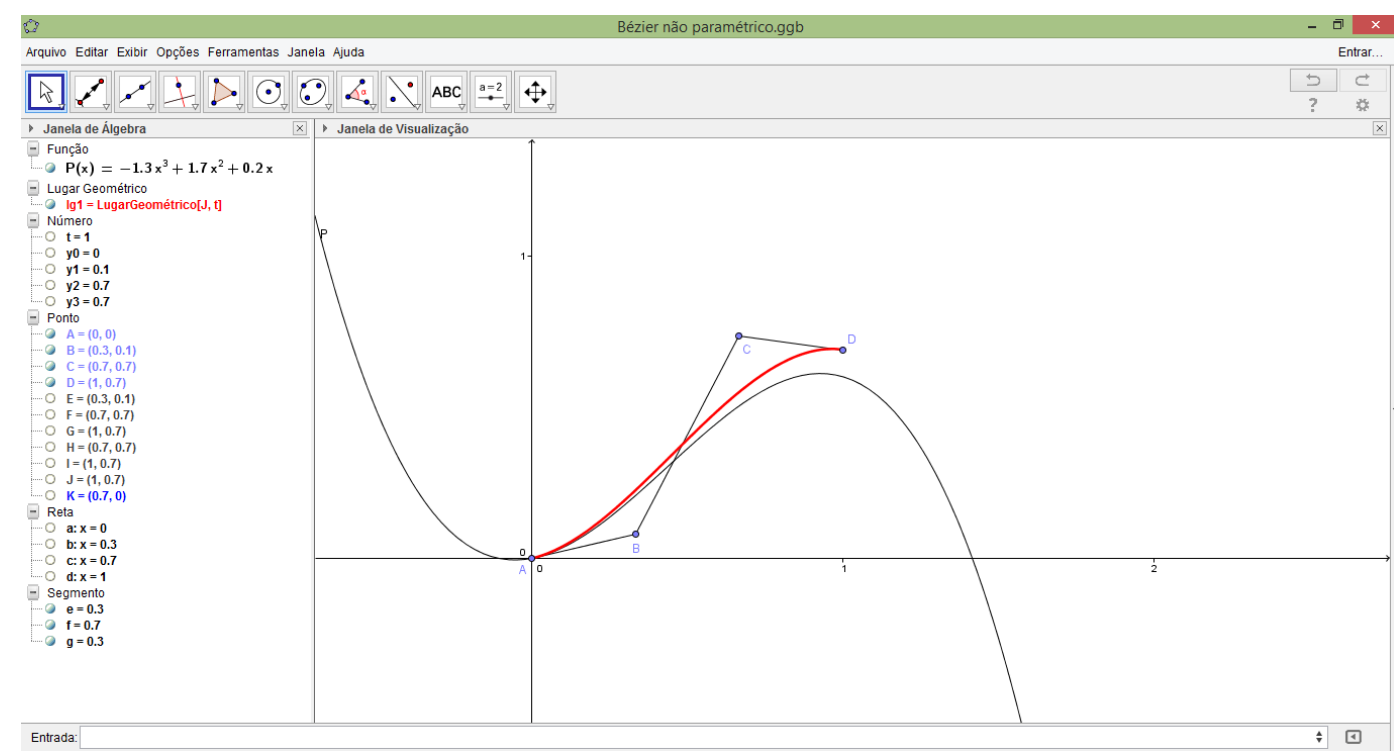

Figura 30: Bézier não paramétrico, janela de visualização mostrando curva de Bézier com uma casa decimal.

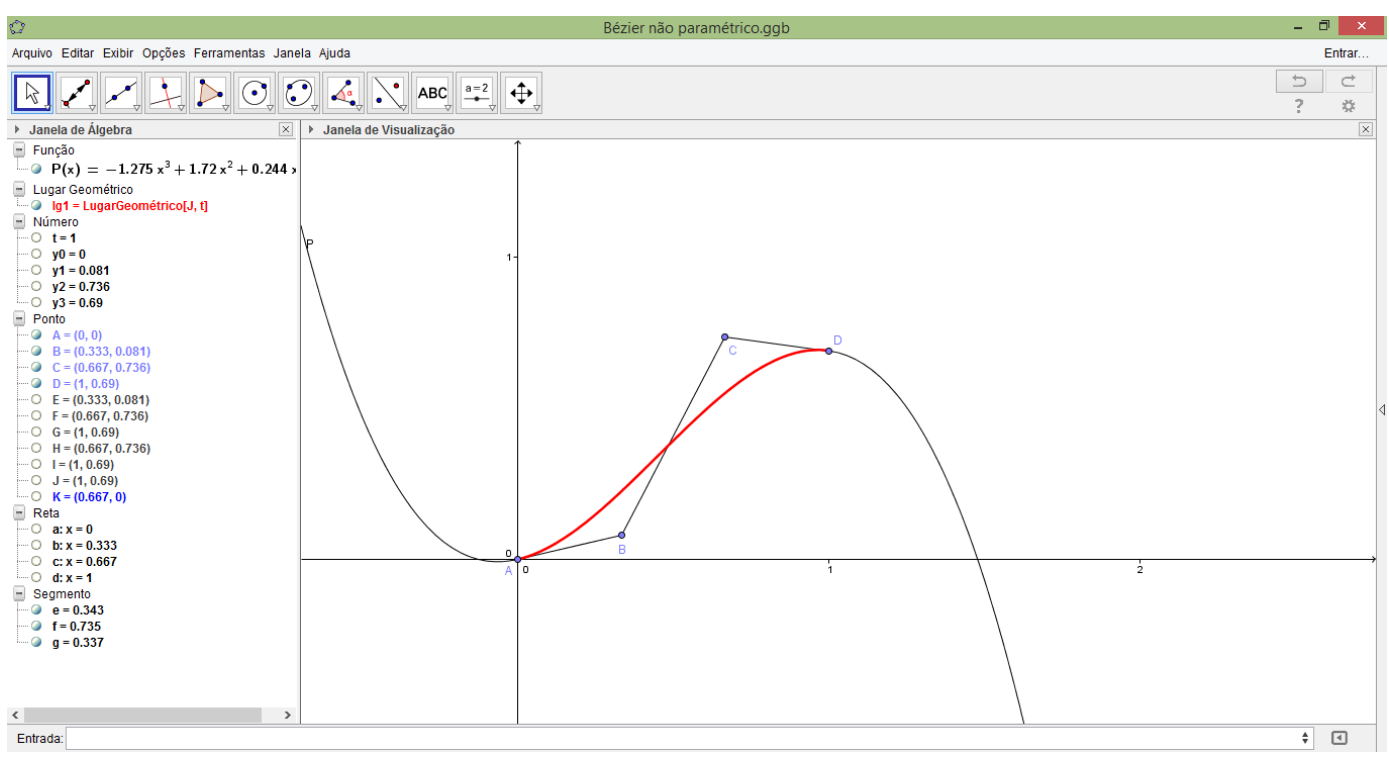

Figura 31: Bézier não paramétrico, janela de visualização mostrando curva de Bézier com três casas decimais.

5a Atividade: Encontrar o polinômio de grau 2 que passa pelos pontos A, B e C. 
Para construir essa atividade basta criarmos 3 controles deslizantes, a, b e c, depois marcamos os três pontos $\mathrm{A}, \mathrm{B}$ e $\mathrm{C}$ e no campo de entrada vamos escrever o polinômio de grau 2: $\mathrm{f}(\mathrm{x})=\mathrm{a} * \mathrm{x}^{\wedge} 2+\mathrm{b} * \mathrm{x}+\mathrm{c}$.

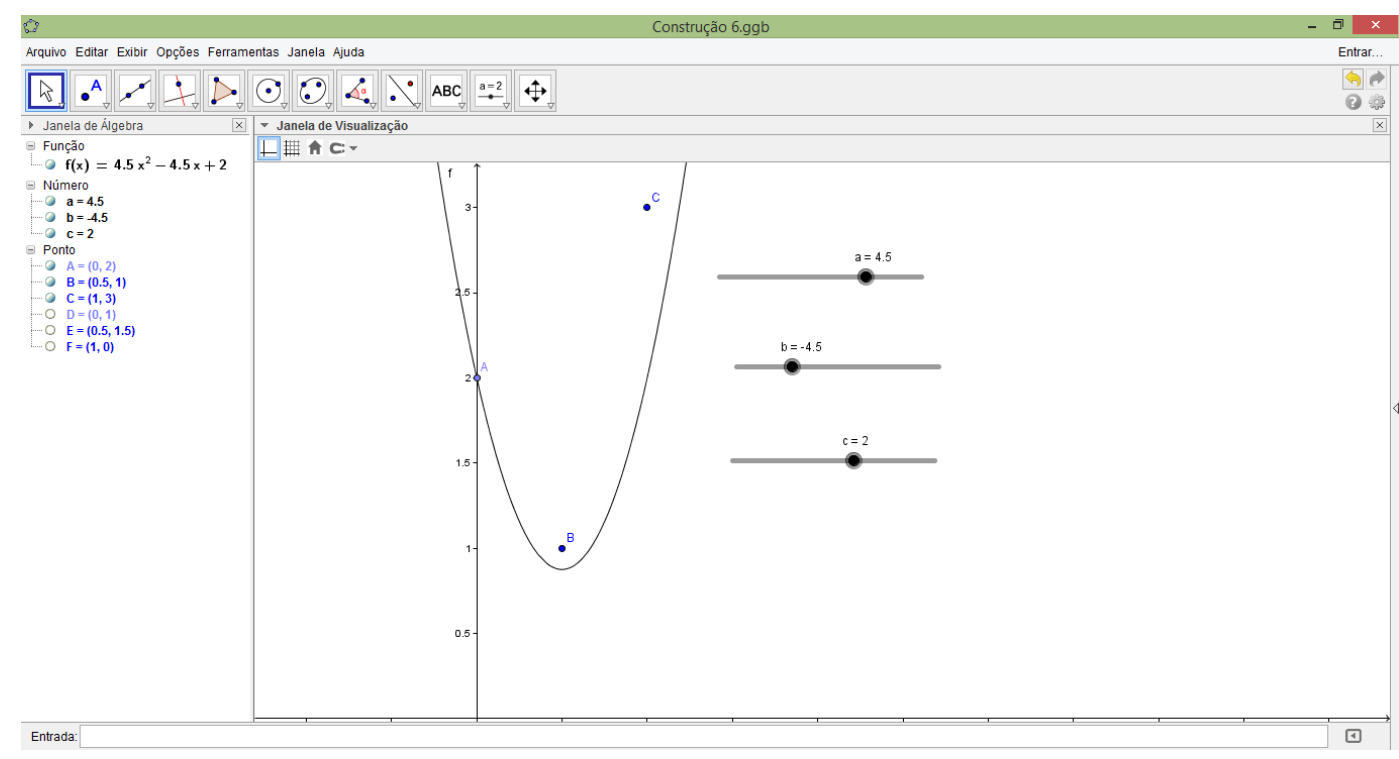

Figura 32: Janela de álgebra mostrando a função gerada pelos coeficientes a, b e c.

O objetivo dessa atividade é bem simples, descobrir os valores de a, b e c, para que a curva passe pelos 3 pontos dados, os alunos deverão fazer a atividade no papel e usar o programa para conferir o resultado. Esse exercício é comum aos alunos do ensino médio, visto que estão familiarizados com polinômios de grau 2 (Anexo 3 - Atividade 4).

6 Atividade: Construção de uma letra

Para essa construção vamos fazer uso da planilha. Primeiro vamos construir um parâmetro $t \in[0,1]$. Marcamos 15 pontos aleatórios. Na coluna A da planilha vamos inserir os pontos, basta apenas escrever: $=\mathrm{A}$, na primeira célula e assim até a letra O. Vejamos:

\begin{tabular}{|c|c|c|c|c|c|}
\hline \multicolumn{6}{|c|}{ - Planilha } \\
\hline \multirow[t]{2}{*}{$f_{x}$} & $\begin{array}{lll}\mathbf{N} & 1\end{array}$ & \multicolumn{2}{|c|}{ 目目目|ロ・ } & \multicolumn{2}{|c|}{ 田 } \\
\hline & A & B & & C & D \\
\hline 1 & $(-2.42,3 \ldots$ & & & & \\
\hline 2 & $=B$ & & & & \\
\hline 3 & & & & & \\
\hline 4 & & & & & \\
\hline 5 & & & & & \\
\hline
\end{tabular}


Figura 33: Inserindo os pontos na planilha.

Na célula B2, vamos escrever A1 + t * (A2 - A1) e copiar para as outras colunas até ficar um único ponto.

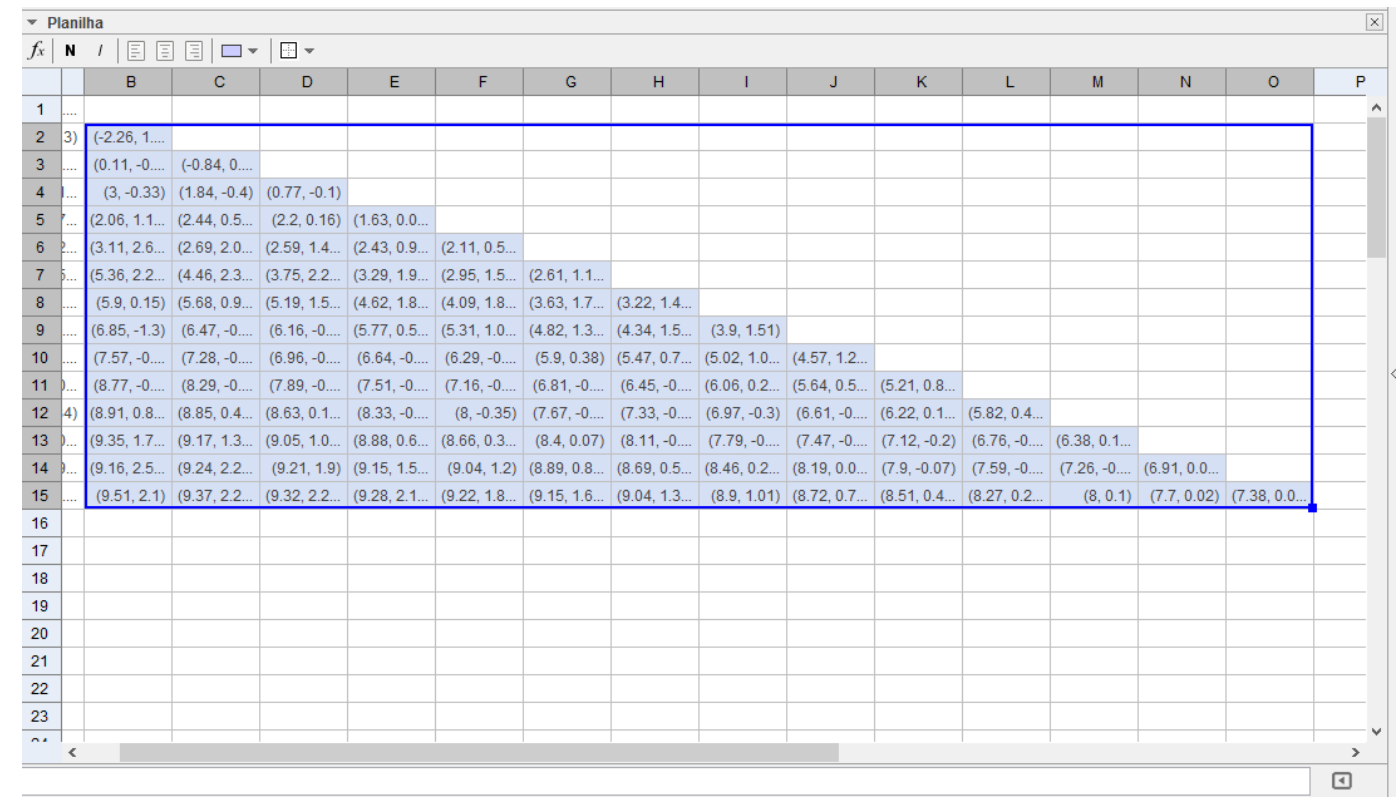

Figura 34: Subníveis gerados na planilha.

O ponto da célula O15 descreve a curva, basta construirmos o lugar geométrico desse ponto conforme t varia e alterarmos o aspecto da curva. Vejamos:

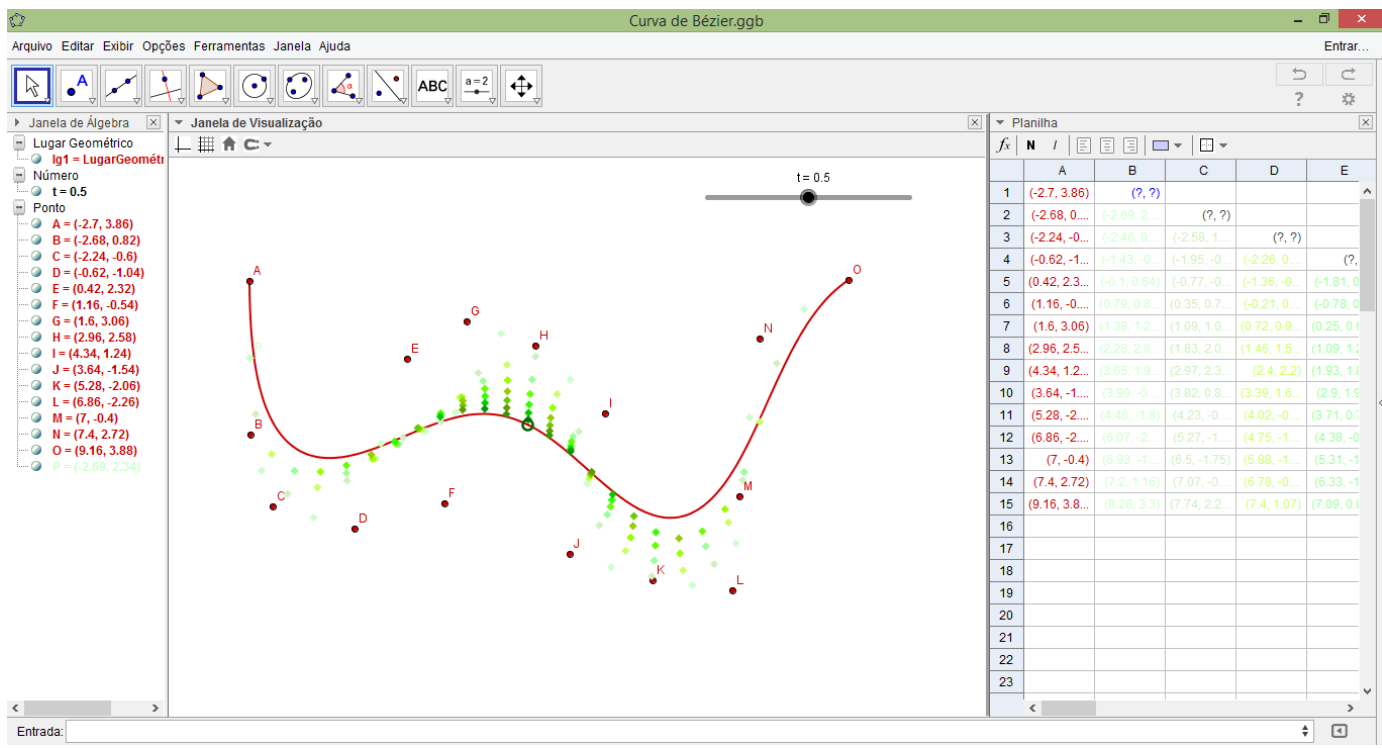

Figura 35: Curva de Bézier e Algoritmo de De Casteljau com seus níveis. 
Nessa atividade os alunos podem visualizar cada nível do algoritmo de De Casteljau, através das cores. O objetivo é mostrar uma aplicação para essa curva, através do desenho de uma letra. Apesar dos alunos estarem motivados, a atividade não pode ser concluída devido à falta de tempo (Anexo 3 - Atividade 5). 


\section{5}

\section{Conclusão}

Nosso objetivo era apresentar uma formulação acessível para o ensino médio. Acreditamos que a formulação via gráfico de função pode contribuir e muito no ensino de polinômios.

Com o modelo "Bézier não paramétrico" o aluno pode obter facilmente a expressão polinomial da curva dados os pontos de controle e é um ótimo auxílio nos cálculos.

As experiências em sala de aula mostraram que a curva de Bézier pode ser introduzida para alunos do ensino médio. Apesar da empolgação, alguns alunos sentiram dificuldade para encontrar a expressão algébrica do polinômio de grau 2 (Atividade 4).

O tempo de trabalho para essa atividade foi de 2 aulas, porém recomendamos um total de 4 aulas para que possam ser feitas revisões de sistemas de equações e gráfico de função. 
6

\section{Referências Bibliográficas}

BRIDGE OF STRINGS, 2008. Disponível em: <http://www.jerusalemite.net/blog/2098/pulling-strings-for-the-bridge-ofstrings>. Acesso em: 14 jan. 2015.

FARIN, Gerald E. Curves and surfaces for CAGD: a practical guide. Third Edition. Arizona: Academic Press, 1992.

FREITAS, Eduardo G. de. Fecho convexo 2D. Disponível em: <http://www.ime.usp.br/ freitas/gc/fecho.html>. Acesso em: 21 jan. 2015.

GROSS, Renan. Bridges, string art and Bézier curves. Disponível em: http://plus.maths.org/content/bridges-string-art-and-bezier-curves. Acesso em: 14 jan. 2015.

JERUSALEM CHORDS BRIDGE. Disponível em: <https://geolocation.ws/v/P/44760982/jerusalem-chords-bridge/en>. Acesso em: 14 jan. 2015.

PAUL DE CASTELJAU. Disponível em: <http://en.wikipedia.org/wiki/Paul_ de_Casteljau>. Acesso em: 7 jan. 2015.

PIERRE BÉZIER. Disponível em: <http://en.wikipedia.org/wiki/Pierre_Bézier>. Acesso em: 8 jan. 2015. 


\title{
Anexos
}

\author{
Anexo 1 \\ CURVAS DE BÉZIER
}

Questionário - 14 de Novembro de 2014

Nome:

Idade: Turma:

1. Para uma construção com 3 pontos de controle, vamos gerar um polinômio de que grau? . E com 5 pontos? . Podemos generalizar para n pontos de controle que o polinômio gerado terá grau:

2. Vimos algumas propriedades das curvas de Bézier, dentre elas observamos que a curva passa por dois pontos de controle. Sejam A, B, C e D, 4 pontos de controle de uma curva. Quais desses pontos pertencem a curva?

3. Construa com lápis e régua, usando o algoritmo de Casteljau, uma curva com 3 ou 4 pontos de controle.

Atividade Computacional - Bézier não paramétrico.

4. Qual polinômio do $2^{\mathrm{o}}$ grau, $\mathrm{p}(\mathrm{x})=\mathrm{ax}^{2}+\mathrm{bx}+\mathrm{c}$, passa pelos pontos $\mathrm{A}=(0,2), \mathrm{B}=\left(\frac{1}{2}, 1\right)$ e $\mathrm{C}=(1,3)$ ? Utilize o arquivo: Construção6 do geogebra para conferir seu resultado.

5. Com o arquivo: Curva de Bézier do geogebra, construa uma letra do nosso alfabeto 
Anexo 2

\section{CURVAS DE BÉZIER}

\section{Resposta dos Alunos - 14 de Novembro de 2014}

\section{Atividade 1 e 2: Curva de Bézier.}

1. Para uma construção com 3 pontos de controle, vamos gerar um polinômio de que grau? $\mathrm{N}$. E com 5 pontos? 4 . Podemos generalizar para $\mathrm{n}$ pontos de controle que o polinômio gerado terá grau: $n+1$

2. Vimos algumas propriedades das curvas de Bézier, dentre elas observamos que a curva passa por dois pontos de controle. Sejam A, B, C e D, 4 pontos de controle de uma curva. Quais desses pontos pertencem a curva?

1. Para uma construção com 3 pontos de controle, vamos gerar um polinômio de que grau? _ 2 _. E com 5 pontos? 4 _. Podemos generalizar para $\mathrm{n}$ pontos de controle que o polinômio gerado terá grau:

2. Vimos algumas propriedades das curvas de Bézier, dentre elas observamos que a curva passa por dois pontos de controle. Sejam A, B, C e D, 4 pontos de controle de uma curva. Quais desses pontos pertencem a curva?

\section{Atividade 3: Algoritmo de De Casteljau.}

3. Construa com lápis e régua, usando o algoritmo de Casteljau, uma curva com 3 ou 4 pontos de controle.

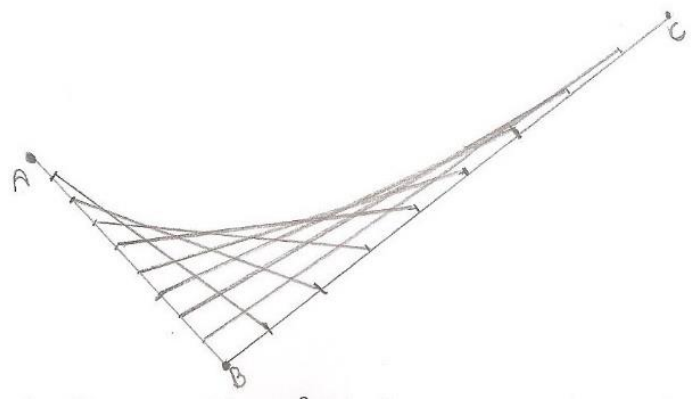

3. Construa com lápis e régua, usando o algoritmo de Casteljau, uma curva com 3 ou 4 pontos de controle.

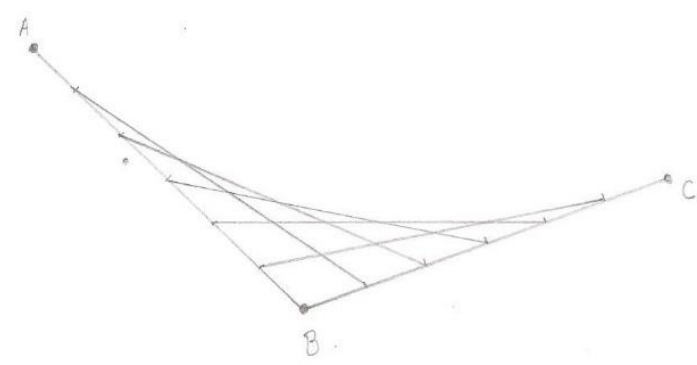


Atividade Computacional: Bézier não paramétrico.

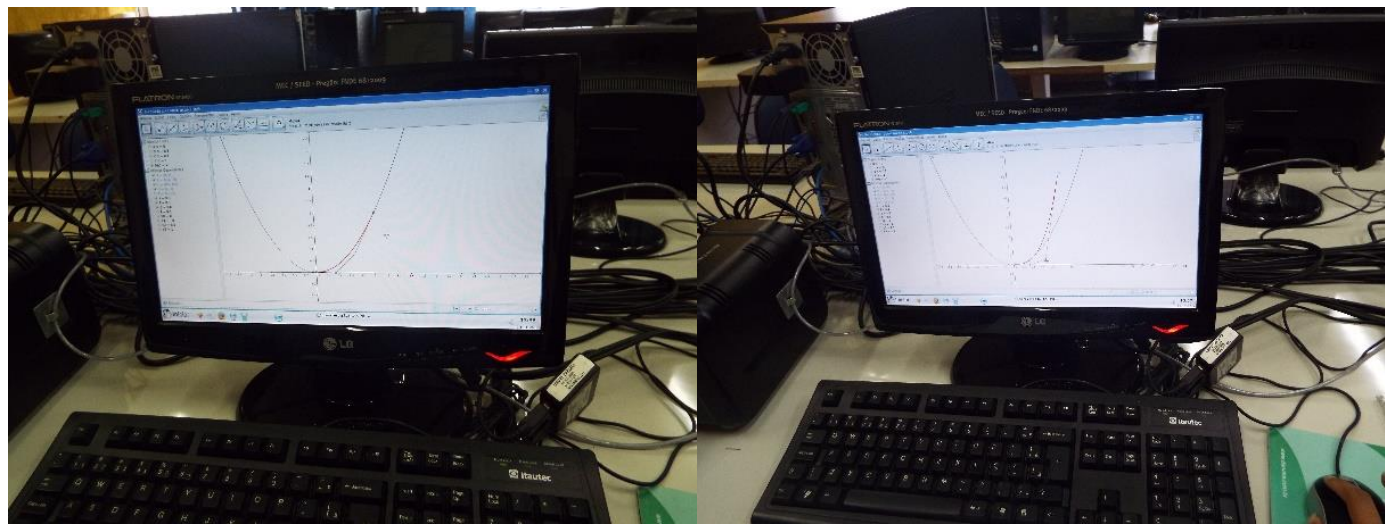

Atividade 4: Polinômio de grau 2.

4. Qual polinômio do 2o grau, $p(x)=a x^{2}+b x+c$, passa pelos pontos $A=(0,2), B=\left(\frac{1}{2}, 1\right)$ e $C=(1,3)$ ? Utilize o arquivo: Construção6 do geogebra para conferir seu resultado. $\left.2=a \cdot 0^{2}+b \cdot 0+c \Rightarrow c=0\right)$
$1=a \cdot\left(\frac{1}{2}\right)^{2}+b \cdot \frac{1}{2}+2$
$\left.1-2=\frac{a+b}{2}=/ 4 a+4 b=-4(x+1)=2+2 b=-4\right)$

4. Qual polinômio do 2o grau, $\mathrm{p}(\mathrm{x})=\mathrm{ax} \mathrm{x}^{2}+\mathrm{bx}+\mathrm{c}$, passa pelos pontos $\mathrm{A}=(0,2), \mathrm{B}=\left(\frac{1}{2}, 1\right)$ e $\mathrm{C}=(1,3)$ ? Utilize o arquivo: Construção6 do geogebra para conferir seu resultado. $\quad 3=a \cdot 1^{2}+b \cdot 1+2$ $Q=a \cdot b^{2}+b \cdot \theta+c=c=2$ $1=a \cdot z+1+a+c=c$

$1-2=\frac{a}{4}+\frac{b}{2}, \frac{4}{4}+\frac{4}{2}=-4(\times 4)=a+2 b=-4$

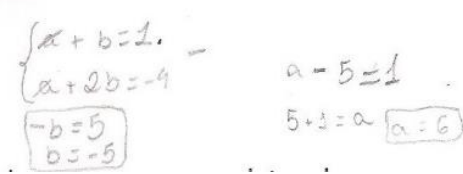

Atividade 5: Construção de uma letra.

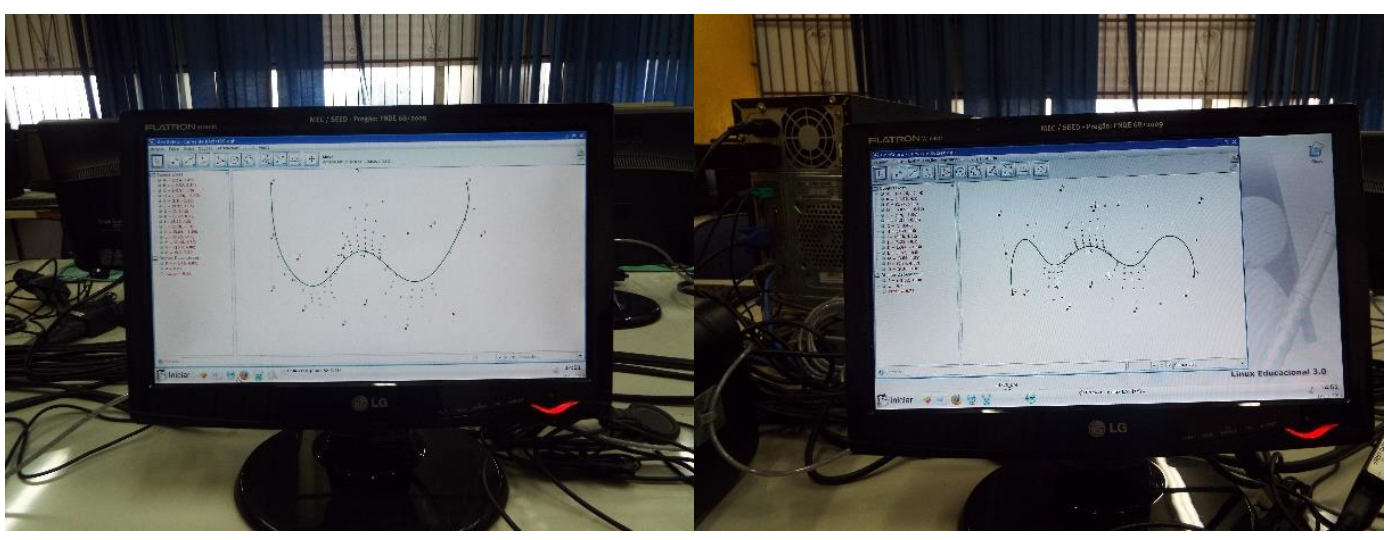


Anexo 3

\section{CURVAS DE BÉZIER}

\section{Auto Avaliação - 14 de Novembro de 2014}

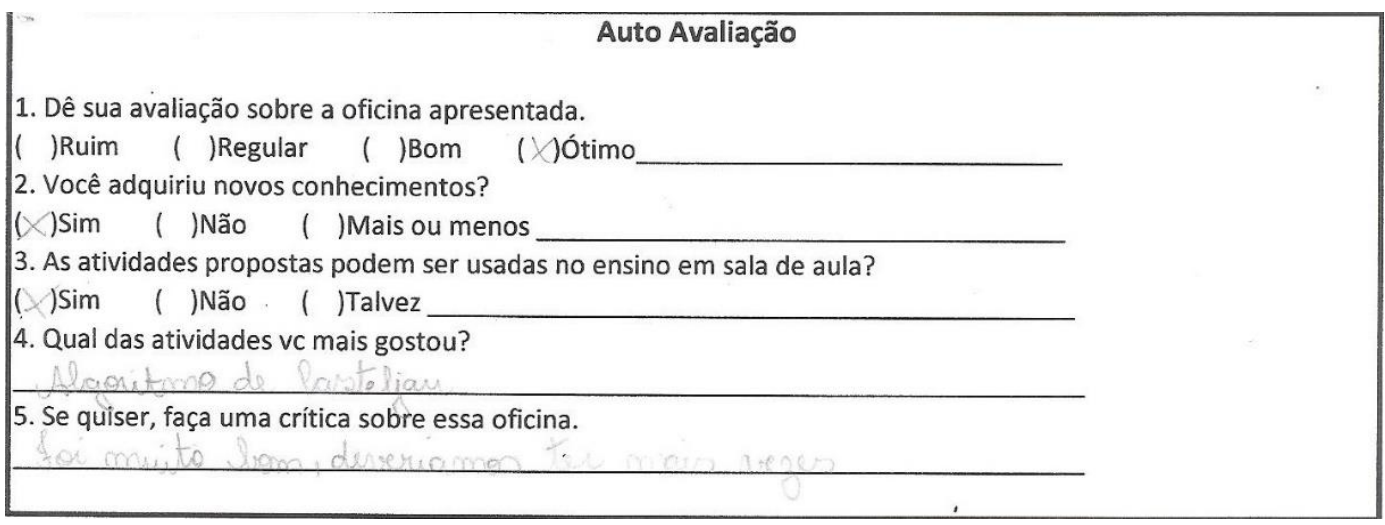

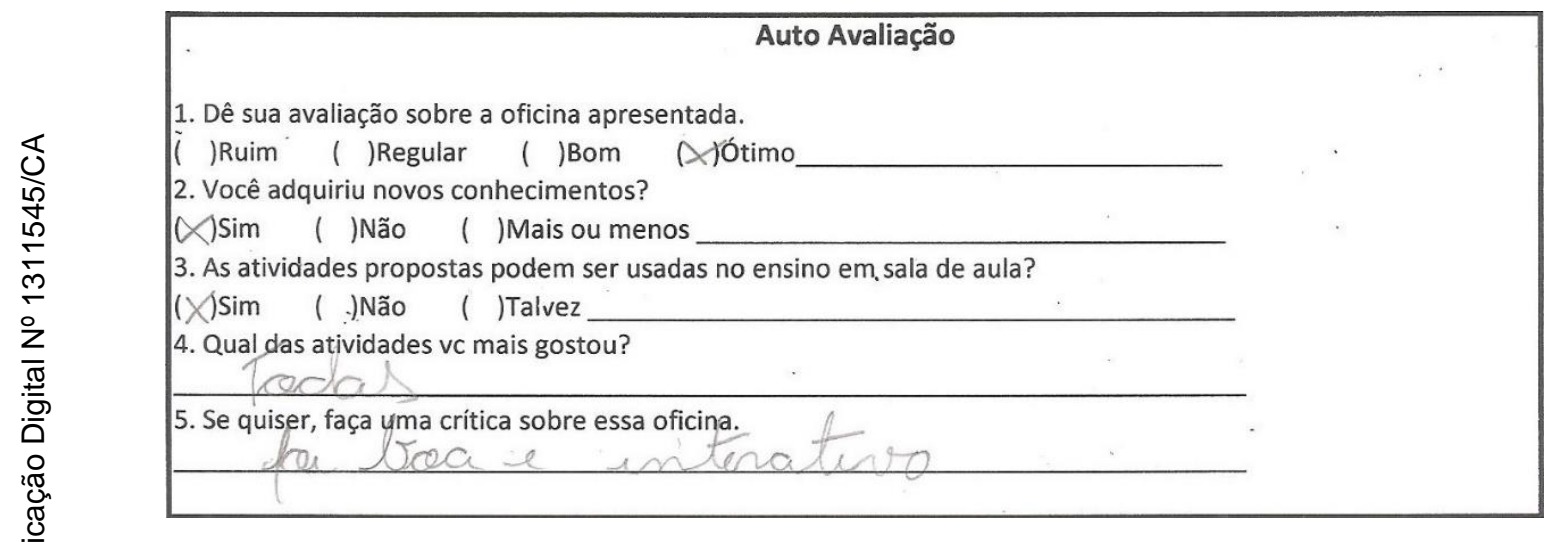

